\title{
Impact of physical activity and energy restriction on immune regulation of cancer
}

\author{
Yitong $\mathrm{Xu}^{1}$, Connie J. Rogers ${ }^{2,3,4}$ \\ ${ }^{1}$ Intercollege Graduate Degree Program in Integrative and Biomedical Physiology, Huck Institutes of the Life Sciences, ${ }^{2}$ Department of Nutritional \\ Sciences, ${ }^{3}$ Center for Molecular Immunology and Infectious Disease, Huck Institutes of the Life Sciences, The Pennsylvania State University, \\ University Park, PA, USA; ${ }^{4}$ Penn State Cancer Institute, Hershey, PA, USA \\ Contributions: (I) Conception and design: All authors; (II) Administrative support: None; (III) Provision of study materials or patients: None; (IV) \\ Collection and assembly of data: All authors; (V) Data analysis and interpretation: All authors; (VI) Manuscript writing: All authors; (VII) Final \\ approval of manuscript: All authors. \\ Correspondence to: Connie J. Rogers, PhD, MPH. Department of Nutritional Sciences, The Pennsylvania State University, University Park, PA 16802, \\ USA. Email: cjr102@psu.edu.
}

\begin{abstract}
Cancer is a major public health issue worldwide. Lifestyle factors, such as body weight and physical activity (PA), significantly impact cancer risk and progression. There is strong evidence that PA reduces and obesity increases risk and mortality from numerous cancer types. Energy restriction (ER) in non-obese hosts significantly reduces tumor incidence in a variety of preclinical models, and reduces body weight and cardiometabolic risk factors in humans. Emerging data suggest that PA- and ER-induced changes in inflammatory and immune mediators may contribute to the cancer prevention effects of these interventions. A systematic literature search was conducted to identify studies that evaluated the impact of PA and ER on tumor and immune outcomes in humans and animal models. A total of 97 eligible studies were identified (68 studies reporting PA interventions and 30 studies reporting ER interventions). Thirtyone studies investigated the effect of PA on cancer immune outcomes using preclinical cancer models of breast $(n=17,55 \%)$, gastrointestinal $(n=6,19 \%)$, melanoma $(n=4,13 \%)$, and several other cancer types $(n=4,13 \%)$. Despite the heterogeneity in study designs, the majority of studies $(n=23,74 \%)$ reported positive effects of PA on tumor outcomes. Thirty-seven clinical studies investigated the effect of PA on cancer immune outcomes. None reported tumor outcomes, thus only immune outcomes were evaluated in these studies. PA studies were conducted in patients with breast $(n=22,59 \%)$, gastrointestinal $(n=5,14 \%)$, prostate $(n=2,5 \%)$, esophageal $(n=1,3 \%)$, lung $(n=1,3 \%)$ cancer, leukemia $(n=1,3 \%)$, or mixed cancer types $(n=5,14 \%)$. Twenty-two studies investigated the effect of ER interventions on cancer immune outcomes using preclinical cancer models including breast $(n=5,23 \%)$, gastrointestinal $(n=5,23 \%)$, lung $(n=2,9 \%)$, liver $(n=2,9 \%)$, pancreatic $(n=2,9 \%)$, and several other cancer types $(n=6,27 \%)$. Positive effects of ER on tumor outcomes were reported in 21 of 22 studies. Six clinical studies investigated the effect of ER (in combination with PA) on tumor immune outcomes in cancer patients with overweight or obesity. Five were conducted in breast cancer patients, and one recruited patients of a mix of cancer types. A wide range of immunological parameters including immune cell phenotype and function, cytokines, and other immune and inflammatory markers were assessed in multiple tissue compartments (blood, spleen, lymph nodes and tumor) in the included studies. Results from preclinical and clinical studies suggest that both PA and ER exert heterogeneous effects on circulating factors and systemic immune responses. PA + ER alters the gene expression profile and immune infiltrates in the tumor which may result in a reduction in immune suppressive factors. However, additional studies are needed to better understand the effect of PA and/or ER on immunomodulation, particularly in the tumor microenvironment (TME).
\end{abstract}


Keywords: Exercise; calorie restriction; aging; cancer risk and progression; immunity

Submitted Feb 05, 2020. Accepted for publication Mar 04, 2020.

doi: $10.21037 /$ tcr.2020.03.38

View this article at: http://dx.doi.org/10.21037/tcr.2020.03.38

\section{Introduction}

Cancer is a major public health problem with an estimated 17 million new cases and 9.5 million cancer deaths in 2018 worldwide (1). Like many chronic diseases, the incidence and prevalence of cancer increase with age (2). Lifestyle factors, such as body weight and physical activity (PA), significantly impact cancer risk and progression. There is strong evidence that PA is associated with reduced risk of breast, colorectal, and endometrial cancer $(3,4)$. Suggestive evidence also exists for the association between PA and reduced risk of cancer in the esophagus, lung and liver $(3,4)$. In addition, PA is associated with decreased cancer recurrence, cancer-specific and all-cause mortality in patients with breast, colorectal and prostate cancer (5-7).

Numerous epidemiological studies demonstrate that overweight and obesity are a strong risk factor for multiple cancer types. The International Agency for Research on Cancer (IARC) working group reported that there is sufficient evidence to conclude that excess body fatness (overweight and obesity) is associated with increased risk of 13 types of cancers including esophagus, gastric, colorectum, liver, gallbladder, pancreas, postmenopausal breast, uterine, ovary, kidney, meningioma, thyroid, and multiple myeloma (8). Although the association between obesity and cancer survival is debated (9), obesity is associated with lower survival in patients with ovarian (10), endometrial (11), and breast cancer $(12,13)$.

Evidence is emerging that weight loss may reduce obesity-associated cancer risk (14). Multiple studies demonstrate a reduction in cancer risk in bariatric surgery patients (15-19) that is attributed specifically to weight loss (20). Among the obesity-associated cancers, bariatric surgery is associated with lower risk of postmenopausal breast, endometrial and colon cancer (21-23). Results from the large Cancer Prevention Study II Nutrition Cohort Study in postmenopausal women suggest that a sustained loss of $10 \%$ of body weight may be associated with a modest reduction in risk for breast cancer (24). However, the minimum amount of weight loss required to reduce obesityassociated cancer risk may differ by cancer site and the type of weight loss intervention utilized. Thus, additional studies are needed to address this question.

ER in non-obese hosts has been studied extensively in animal models and is the only known intervention to prolong lifespan in numerous species, including non-human primates $(25,26)$. Furthermore, ER in non-obese hosts can reduce tumor incidence and progression in a variety of preclinical tumor models $(27,28)$. In humans, two years of total energy or calorie restriction was evaluated in the CALERIE-2 (Comprehensive Assessment of Long-term Effects of Reducing Intake of Energy) trial to assess the effect of ER on biomarkers of longevity and cardiometabolic risk among non-obese adults (29). The calorie-restricted group achieved $11.9 \% \pm 0.7 \%$ ER over two years and had lower body weight, waist circumference and fat mass compared to the control group at 24 months (30). Furthermore, ER in non-obese adults reduces cardiometabolic risk factors, including LDL-cholesterol, total cholesterol to HDLcholesterol ratio, systolic and diastolic blood pressure and the inflammatory mediator, C-reactive protein (CRP) (31). However, no data on cancer outcomes has been reported from this trial.

Despite compelling observational and experimental data supporting the association between changes in host energy balance and cancer outcomes, the underlying mechanisms are not completely understood. Previous studies suggest that changes in metabolic, endocrine, inflammatory and immune mediators may contribute to the cancer prevention effect of PA and ER (32-34). The metabolic and endocrine pathways altered by PA and ER are reviewed elsewhere (34-36). Emerging data suggest that PA- and ER-induced changes in inflammatory and immune mediators may also be important mediators underlying the cancer prevention effects of these interventions, and is the focus of this review.

The fundamental role of the immune system in tumor development has long been recognized and involves a complex network of pro- and anti-tumor mediators. CD8 ${ }^{+}$ cytotoxic T cells (CTLs) and natural killer (NK) cells are primarily responsible for the killing of tumor cells, while $\mathrm{CD}^{+}$helper $\mathrm{T}$ cells can enhance their cytotoxic function by producing cytokines such as IFN $\gamma(37,38)$. However, immunosuppressive cells from both the myeloid [myeloid- 
derived suppressor cells (MDSCs)] and the lymphoid [regulatory $\mathrm{T}$ cells (Tregs), a subset of $\mathrm{T}$ cells with immune suppressive capacity] lineages are also recruited in response to tumor-derived signals to facilitate immune escape $(37,38)$. In addition, a wide variety of cytokines and chemokines also play important roles in dictating the immune and inflammatory milieu and the function of immune cells $(37,38)$.

In healthy humans or rodent models, regular, moderate intensity PA enhances neutrophil, NK cell and T cell function, enhances vaccine responses, reduces $\mathrm{T}$ cell exhaustion, and alters inflammatory responses (39-42). $\mathrm{PA}$ also ameliorates and delays immunosenescence, the deterioration of the immune system with advanced age, which is postulated to contribute to an increase in cancer risk $(2,43)$. Less is known about the effects of PA on immune function in tumor-bearing hosts. Emerging evidence suggest that PA may result in an increase in effector cell number and function, a reduction in immunosuppressive cells, and an altered cytokine profile in tumor-bearing animals $(32,44,45)$. However, a definitive link between PA and improved cancer immunity is yet to be established.

The beneficial effects of ER on immune function include a reduction in chronic inflammation and a delay in immunosenescence. Animal studies suggest that ER reduces pro-inflammatory cytokines produced by mononuclear cells, as well as in the circulation $(27,28,46)$. In addition, ER maintains naïve $T$ cell numbers and $T$ cell proliferation capacity in both aged rodents and non-human primates $(27,47)$. How ER may be modulating host immunity in tumor-bearing hosts is not well understood. Studies in preclinical cancer models demonstrate that ER may result in a reduction in tumor-infiltrating macrophages, MDSCs, and circulating and intratumoral pro-inflammatory mediators $(34,45)$.

Several reviews have summarized the effect of PA on tumor outcomes, or the potential mechanisms underlying the effect of PA on immune function at various stages of cancer development $(32,33,48-51)$. The cancer prevention effect and potential changes in cancer immunity induced by ER have also been discussed briefly in several reviews $(27,28,34,52)$. However, no studies have assessed the evidence linking potential immune mechanisms to the beneficial effect of PA and ER across the cancer continuum. Therefore, the objective of the current review was to evaluate and summarize the findings from both preclinical and clinical studies that have examined the effect of PA and/ or ER on immune outcomes in tumor-bearing hosts.

\section{Methods}

\section{Search strategy}

A systematic literature search was conducted using PubMed (Medline), Web of Science and CENTRAL to identify studies that evaluate the impact of PA and ER on tumor and immune outcomes in animal models and in humans. The search strategy included three sets of search terms: (I) PA, ER, and related terms; (II) immunological parameters including cellular and molecular mediators of immunity and inflammation, key immunological events and immunotherapy; (III) cancer of all types (complete search strategy provided in Table S1). Supplemental searching by hand was also conducted to identify additional studies from the reference lists of relevant review and primary research articles.

\section{Inclusion and exclusion criteria}

Only primary research articles written in the English language were included. Intervention studies conducted in preclinical cancer models or human cancer patients were included, while observational studies or intervention studies conducted in non-cancer subjects were excluded. Eligible preclinical studies must have reported the effect of energy balance interventions on tumor outcomes (tumor incidence, growth, metastasis or survival). Few clinical studies investigated the effect of energy balance interventions on tumor outcomes; therefore, this criterion was not applied to clinical studies. We focused on studies that evaluated the effect of chronic, aerobic activity (such as running and swimming) as the intervention. Studies performing resistance exercise, conditioning or stretching exercise (e.g., Tai Chi or yoga), or a single bout of exercise were excluded. Numerous studies combined resistance exercise with aerobic exercise interventions to prevent muscle wasting and cachexia in cancer patients. Therefore, we included clinical studies that applied a combination of aerobic and resistance exercise, and excluded studies that solely used resistance exercise training. Because weight loss and wasting are common phenomena in late-stage cancer patients experiencing cancer cachexia, we excluded studies that reported weight loss as a secondary outcome to cancer progression, and only included studies performing intentional weight loss intervention via $\mathrm{PA}$ and/or ER. Included studies must have assessed immune outcomes, including immune cell number and/or function, gene expression or protein level of immune and inflammatory 
markers. Studies that included multiple interventions (such as those investigating the effect of PA and chemotherapy as single intervention or in combination) were included, as long as it was possible to compare between no intervention and energy balance intervention alone groups.

\section{Study selection, data extraction and analysis}

EndNote software was used to manage records from the literature search. After de-duplication, the titles and abstracts of all obtained records were first reviewed to determine whether each record met the inclusion criteria. Potentially eligible studies were further reviewed on the full texts to determine the eligibility based on the inclusion and exclusion criteria. Findings were summarized separately on the effect of PA and ER, with each category further divided into preclinical and clinical findings.

\section{Results}

A Preferred Reporting Items for Systematic Reviews and Meta-Analyses (PRISMA) (53) flow diagram is shown in Figure S1. A total of 97 eligible studies were identified, including 68 studies ( 31 preclinical and 37 clinical studies) reporting PA interventions, and 30 studies ( 24 preclinical and six clinical studies) reporting ER interventions. One preclinical study (45) investigated the effects of PA and ER separately and in combination, and was included in the summary of both PA and ER studies.

\section{Effects of PA on cancer immune outcomes}

\section{Preclinical findings}

Thirty-one studies investigated the effect of PA interventions on cancer immune outcomes using preclinical (mouse or rat) cancer models (Table 1). Breast cancer was the most studied cancer type $(\mathrm{n}=17,55 \%)(45,54-69)$, followed by gastrointestinal cancer $(\mathrm{n}=6,19 \%)(70-75)$, melanoma $(\mathrm{n}=4,13 \%)(44,76-78)$ and several other cancer types $(n=4,13 \%)(79-82)$. Transplantable, carcinogeninduced and genetically-engineered (spontaneous) cancer models were used. Among the transplantable tumor models, subcutaneous (s.c.) inoculation was the most common route of tumor inoculation. Orthotopic (intramammary) inoculation was applied in four studies using breast cancer models $(45,57,58,61)$ to mimic the natural tissue environment of mammary tumorigenesis. Several studies inoculated tumor cells via intravenous (i.v.) $(62,78-80)$ or intraperitoneal (i.p.) routes (81) where no primary tumors were formed, thus lung metastasis and peritoneal fluid were assessed as tumor outcomes, respectively. All studies reporting intestinal cancer outcomes (70-75) used carcinogen-induced or genetically-engineered cancer models, and intestinal lesions (aberrant crypt foci or polyps) were assessed as indicators of tumorigenesis.

PA modalities included voluntary wheel running, treadmill running and swimming. The frequency, intensity, duration of individual PA sessions, and the length of total PA intervention period were highly heterogeneous. Furthermore, the window of PA intervention in relation to the cancer continuum was also variable. Despite the heterogeneity in study designs, the majority of studies $(n=23,74 \%)$ reported positive effects of PA on tumor outcomes including reduced tumor incidence, tumor growth, metastases, and improved survival. Six studies (19\%) $(62,64,69,76,78,79)$ reported null effects, and two studies $(6 \%)(66,80)$ reported negative effects of PA on tumor outcomes.

Commonly reported immune outcomes included immune cell phenotype and function, cytokines and other immune and inflammatory markers. Tumor, spleen and blood were the most frequently assessed tissue compartments. In the spleen, the percentage and/or number of NK cells was increased in two studies $(77,80)$ and unchanged in one study (79), while NK cell cytotoxicity was increased in three studies $(62,79,80)$ and unchanged in one study (44). One study reported no change in the number of splenic $\mathrm{T}$ cells (77), and two studies reported mixed findings on $T$ cell functional markers $(57,77)$. Increased $\mathrm{CD}^{+} \mathrm{T}$ cell proliferation (by PA+ER) (45) and macrophage phagocytic activity (81) were each reported in one study. Circulating immune cell populations were assessed in three studies, with two null findings $(66,75)$ and one reporting an increase in total leukocytes, neutrophils, and monocytes (61). Among the serum inflammatory markers evaluated, TNFa was reduced in three studies $(68,70,72)$ and increased in one study $(55)$, IL-6 was reduced in three studies $(65,72,74)$ and unchanged in one study (59), MCP-1 was reduced in one study (65) and unchanged in two studies $(58,78)$, and CRP was unchanged in two studies $(59,68)$. A few studies also assessed immune outcomes in other tissue compartments. One study reported an increase in the percentage of $\mathrm{CD}^{+} /$ IFN $\gamma^{+}$cells in the tumor-draining lymph node (TDLN) (77), and three other studies reported an increase in lymphocyte proliferation from the non-TDLN $(55,56,76)$.

Among the tumor immune infiltrates, the percentage 


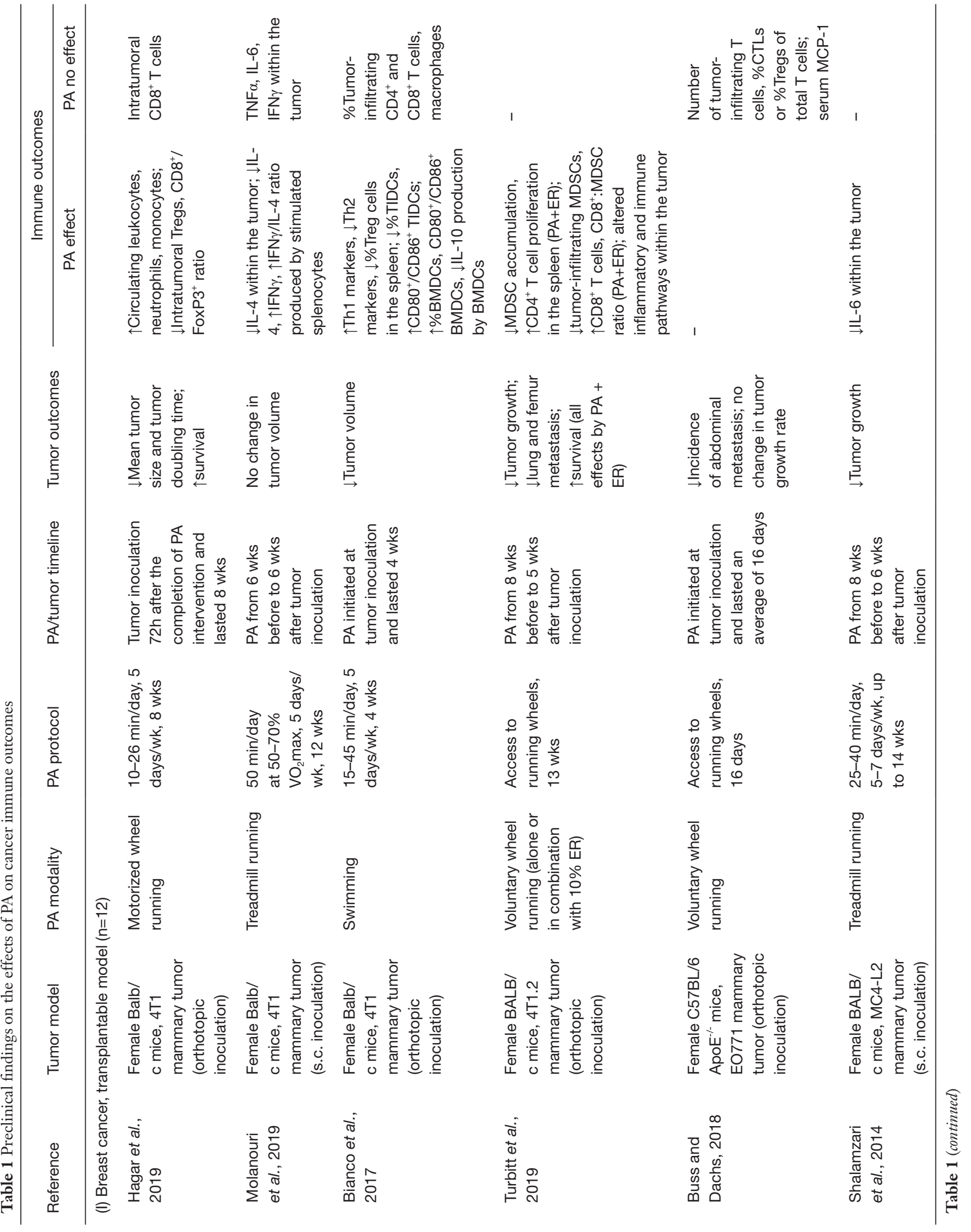




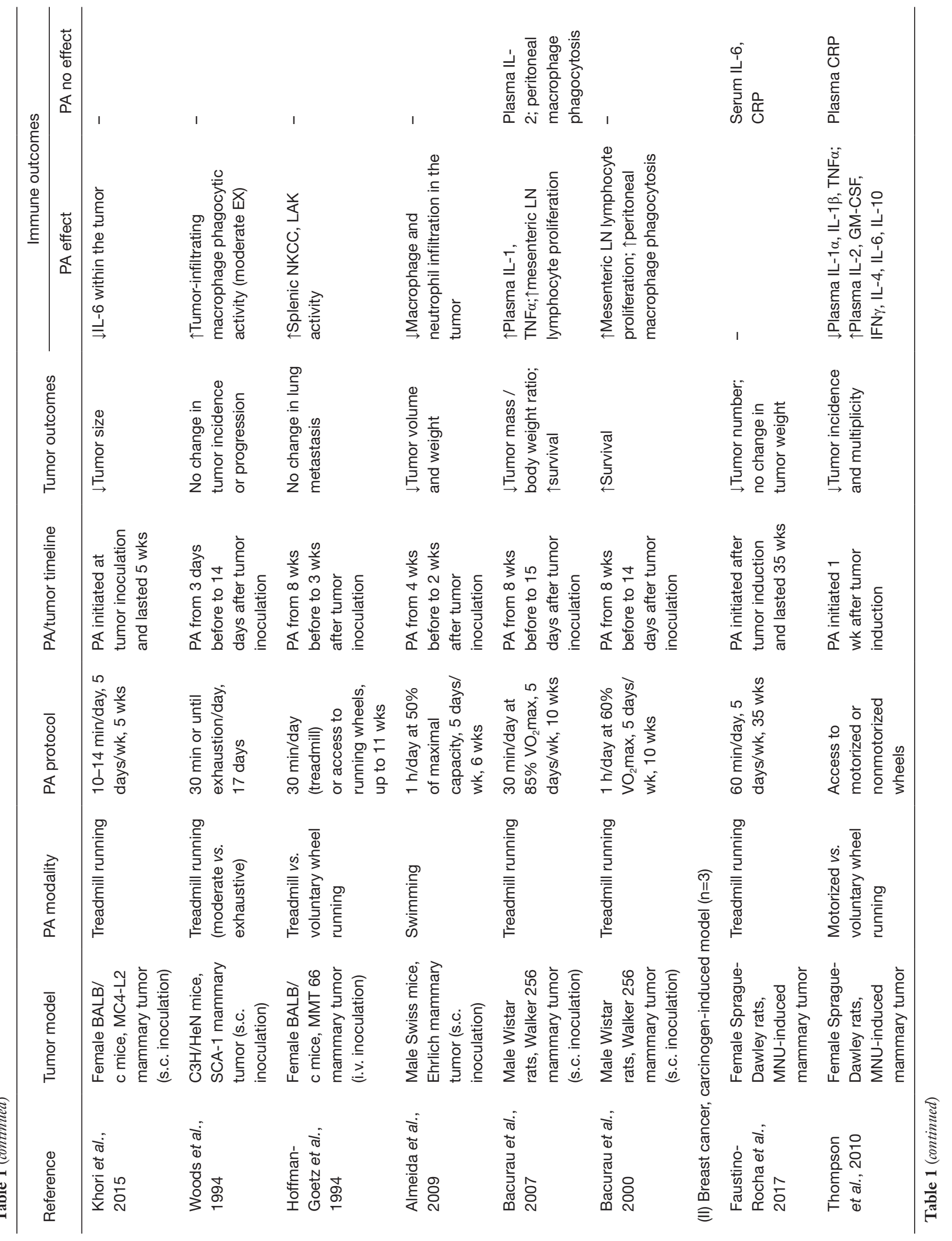




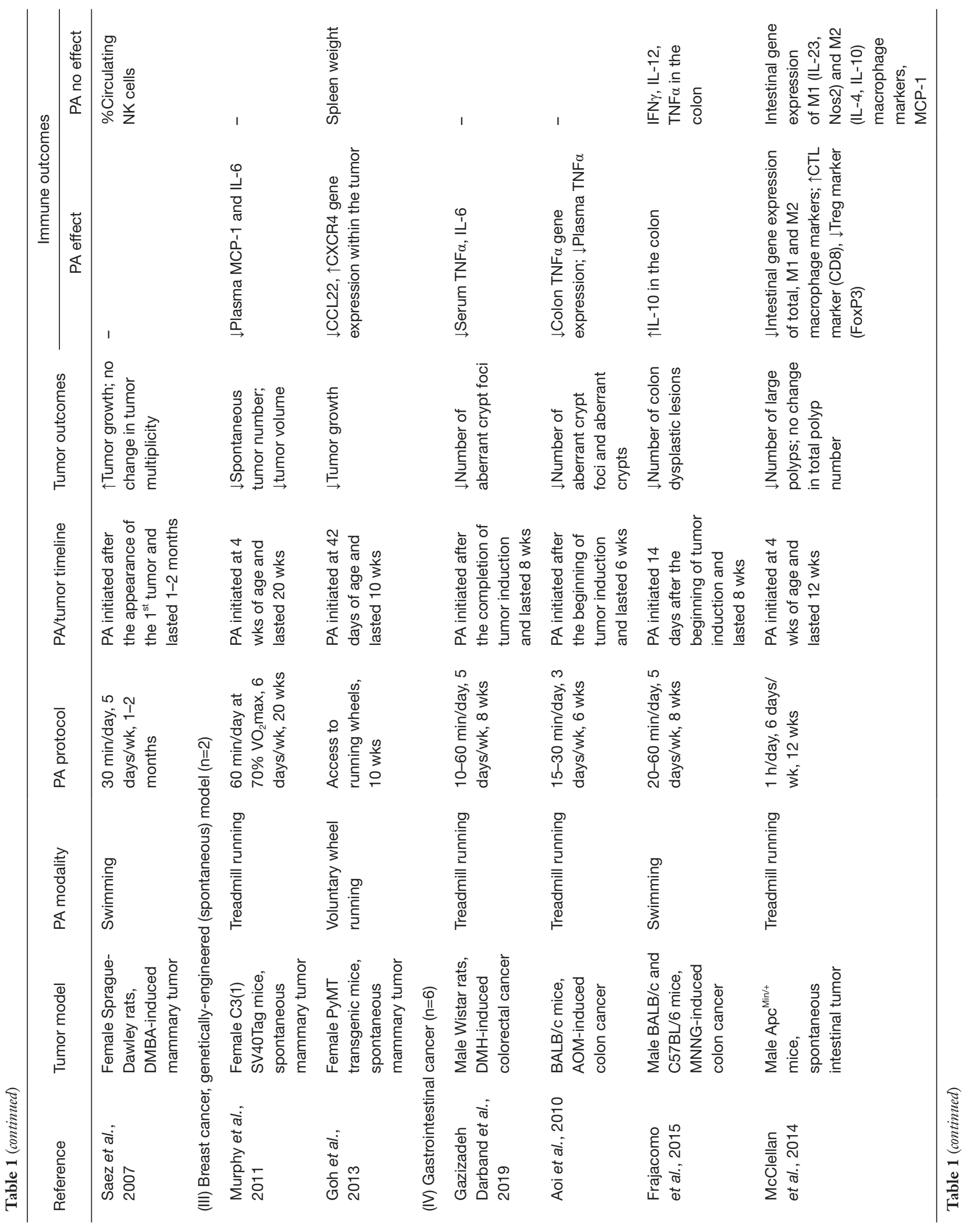




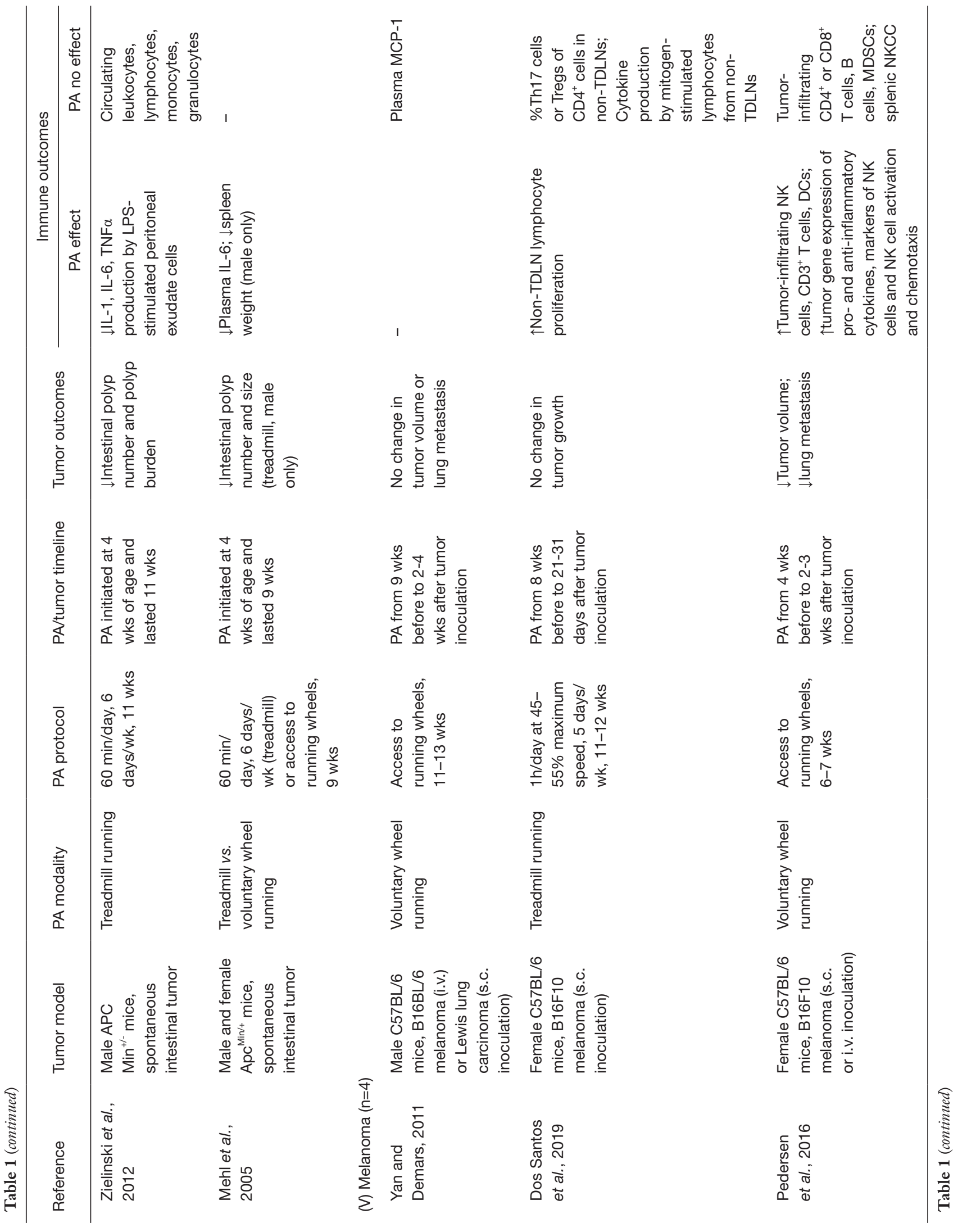




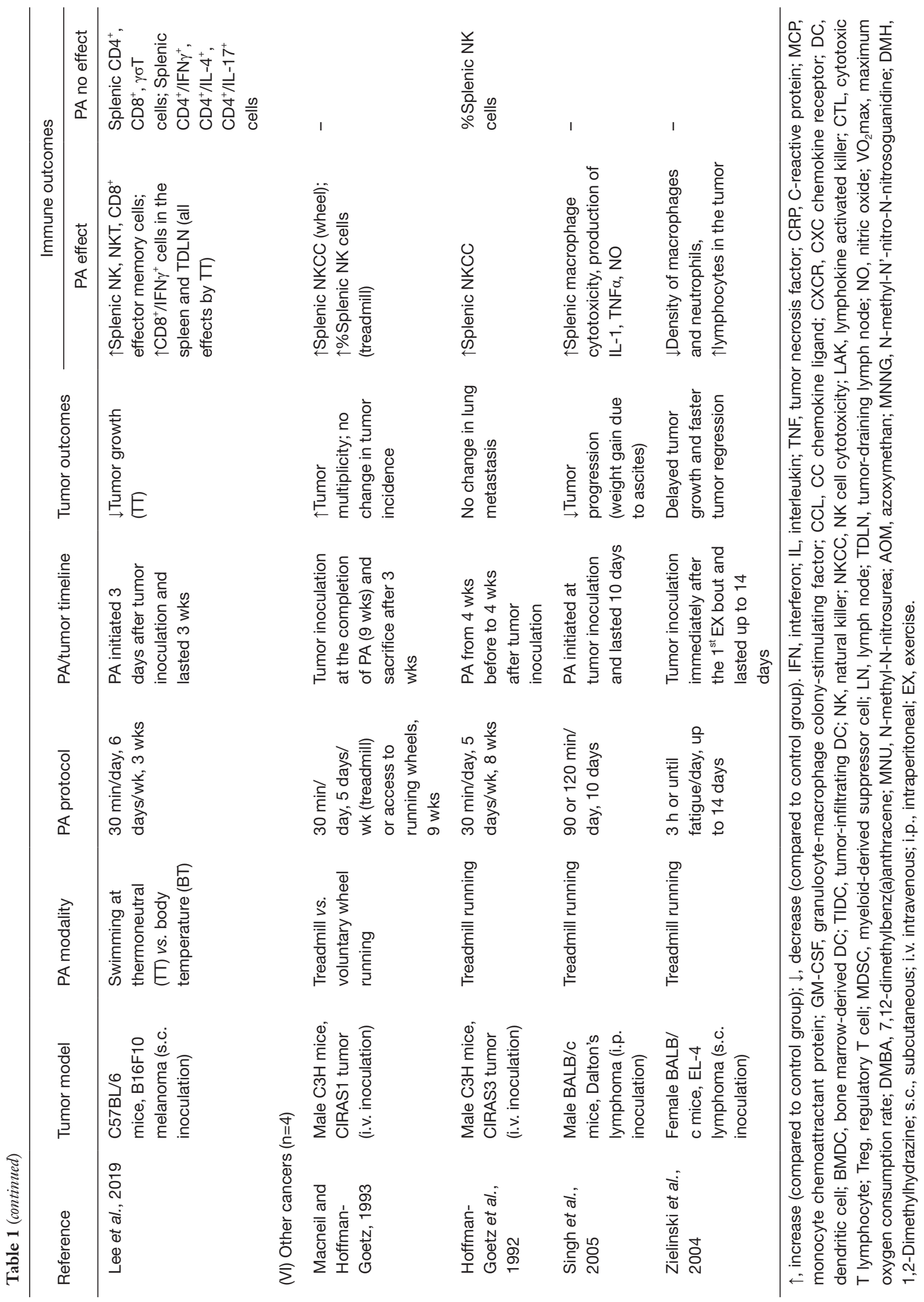


and/or number of $\mathrm{T}$ cells was increased in three studies $(44,45,73)$ and unchanged in three studies $(57,58,61)$. The percentage of NK cells was increased in one study (44), Tregs was reduced in two studies $(61,73)$ and unchanged in one study (58). The percentage of MDSCs was reduced in one study by the combination of PA+ER (45). The percentage and/or number of macrophages was reduced in three studies $(54,73,82)$ and unchanged in one study $(57)$; and the phagocytic activity of tumor-infiltrating macrophages was increased in one study (69). The percentage of dendritic cells (DCs) was increased (44) or reduced (57), respectively, in one study, and the percentage of neutrophils was reduced in two studies $(54,82)$. In addition to the infiltrating immune cells, several studies reported mixed findings on immune and inflammatory markers within the tumor. TNF $\alpha$ was increased in one study (44), reduced in one study (70), and unchanged in two studies $(64,71)$. IL-6 was increased in one study (44), reduced in two studies $(63,67)$, and unchanged in one study (64). IFN $\gamma$ was increased in one study (44), reduced in one study (45), and unchanged in two studies $(64,71)$. Two studies assessed the gene expression profile within the tumor microenvironment (TME) in a melanoma (44) or breast cancer (45) model, respectively, and both found global changes in an array of immune and inflammatory mediators including cytokines, chemokines and receptors, and multiple immune inhibitory molecules.

\section{Clinical findings}

Thirty-seven clinical studies investigated the effect of PA interventions on cancer immune outcomes (Table 2). The majority of studies were conducted in patients with breast cancer $(\mathrm{n}=22,59 \%)(83-104)$. Other studies involved patients with gastrointestinal cancer $(\mathrm{n}=5,14 \%)(105-109)$, prostate cancer $(\mathrm{n}=2,5 \%)(110,111)$, esophageal cancer $(\mathrm{n}=1,3 \%)$ (112), lung cancer $(\mathrm{n}=1,3 \%)(113)$, leukemia $(\mathrm{n}=1,3 \%)(114)$ or mixed cancer types $(\mathrm{n}=5,14 \%)$ (115-119). Twenty-two studies used solely aerobic exercise interventions and fifteen studies used a combination of aerobic and resistance exercise interventions. Treadmill and cycle ergometer were most frequently used in the aerobic exercise sessions. Similar to preclinical PA studies, much heterogeneity existed in all aspects of PA prescription (frequency, duration, intensity, and length of intervention period). Several clinical studies used a single-group design where all participants performed the PA intervention. As a result, no comparison can be made between the PA intervention and sedentary control. Instead, immune outcomes pre- and post-PA intervention were compared.

The timing of the PA intervention in relation to cancer treatment may significantly affect cancer immune outcomes. Therefore, we classified the included studies into three categories: PA interventions given before, during, and after treatment. The existing evidence base only includes two pre-treatment (pre-surgical) $(94,113)$ and eight duringtreatment $(93,95,101,110,114,115,117,119)$ PA studies, while the majority of studies $(n=27)$ assessed the effect of PA interventions post-cancer treatment.

Most included studies assessed the effect of PA intervention on serum immune and inflammatory cytokines, the majority of which reported null results $(83,85,87-92,94,99,100,102,103,105,108,110,115-117,119)$. Several studies also compared post-PA intervention to pre-PA intervention serum cytokine levels, with mixed results showing either a reduction $(84,104,107,112,114)$ or no change in serum cytokines after the PA intervention $(84,104,106,107,111-114,118)$.

Circulating immune cell phenotype and function were also commonly evaluated. When comparing the PA intervention group to the sedentary control, the percentage and/or number of $T$ cells was increased in one study (116) and unchanged in four studies $(90,96,101,115)$, while no change was found by any study in circulating B cells, NK cells, monocytes or neutrophils. Regarding immune cell function, NK cell cytotoxicity was increased in two studies $(86,109)$ and unchanged in two studies $(96,115)$, lymphocyte proliferation was increased in two studies $(86,90)$, and lymphocyte cytokine production was reported in four studies with mostly no change $(83,86,90,105)$. When comparing post-PA intervention to pre-intervention, one study reported a reduction in the percentage of lymphocytes and monocytes and an increase in granulocytes (98), while two other studies reported no change in the percentage of $\mathrm{T}$ cells or NK cells $(93,97)$. One study reported increased NK cell cytotoxicity post PA intervention (97).

Due to limited access to tumor tissue biopsies, most clinical studies evaluated immune outcomes only in the blood, with only one exception where tumor samples were analyzed after a pre-surgical PA intervention (94). In this study, a pre-surgical exercise intervention lasting approximately a month resulted in global changes in the gene expression profile within the TME, with an upregulation of pathways involved in immune cell function and inflammatory signaling reported in the exercise compared to the sedentary control group. A trend toward a decrease in the percentage of tumor-infiltrating Tregs 


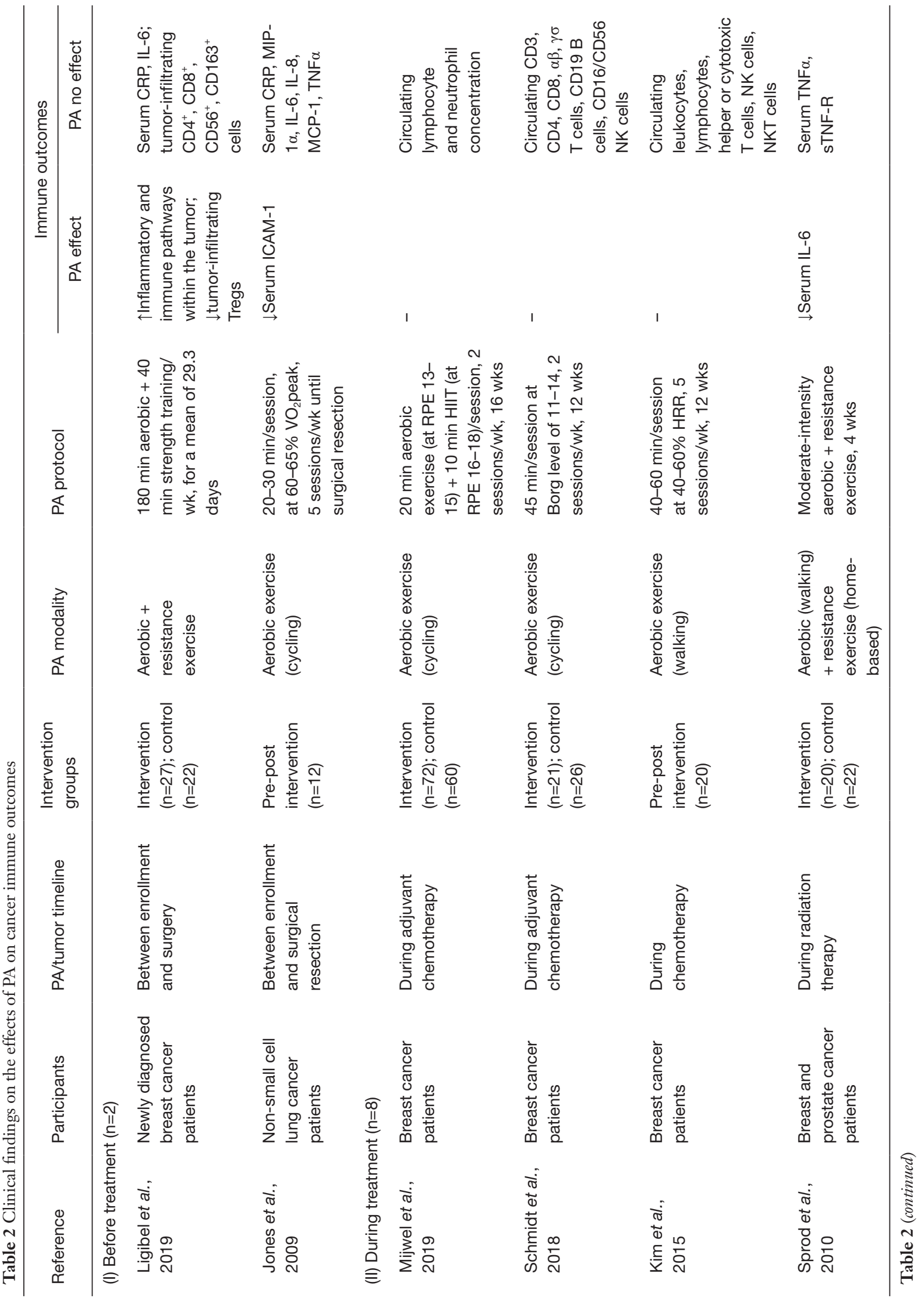




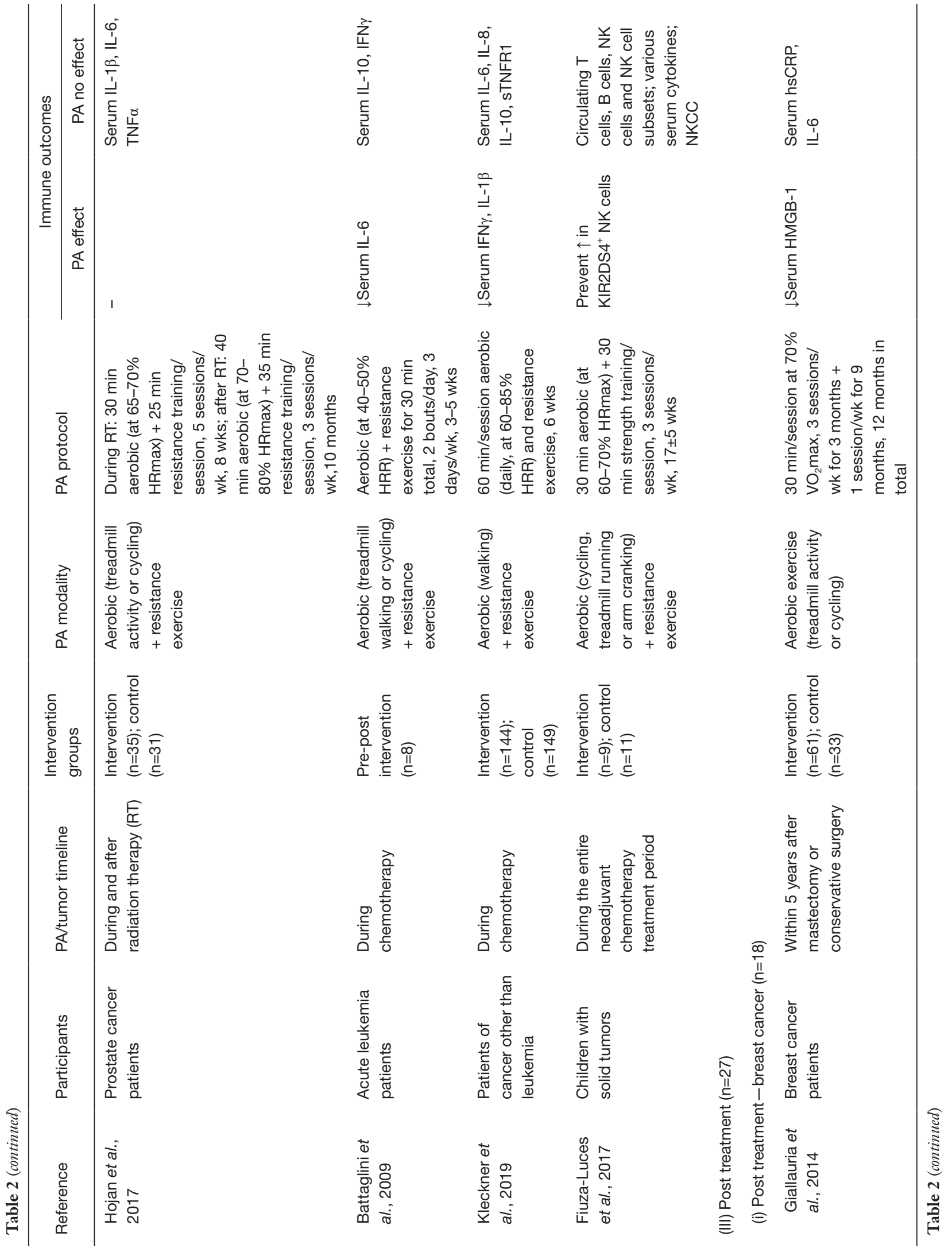




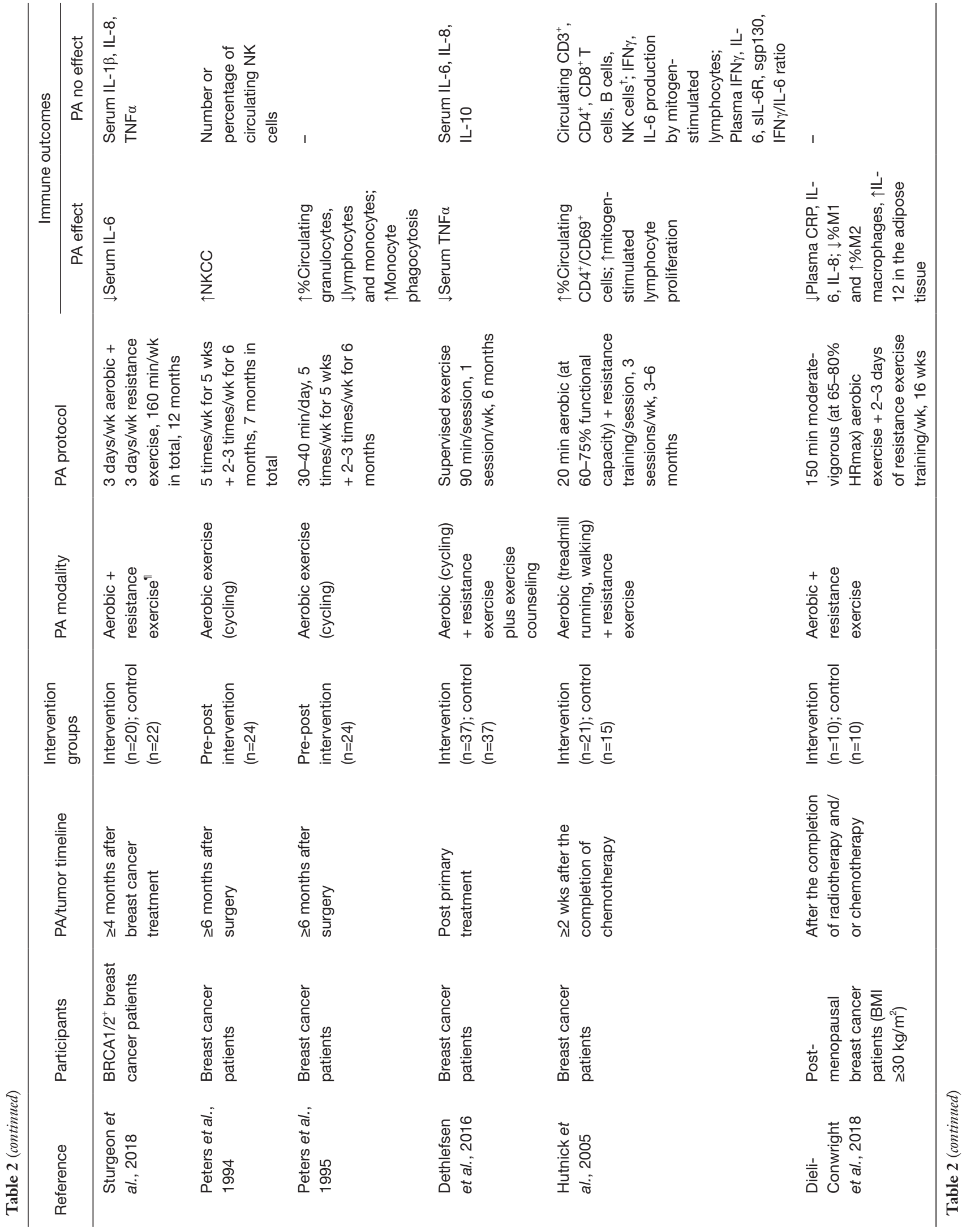




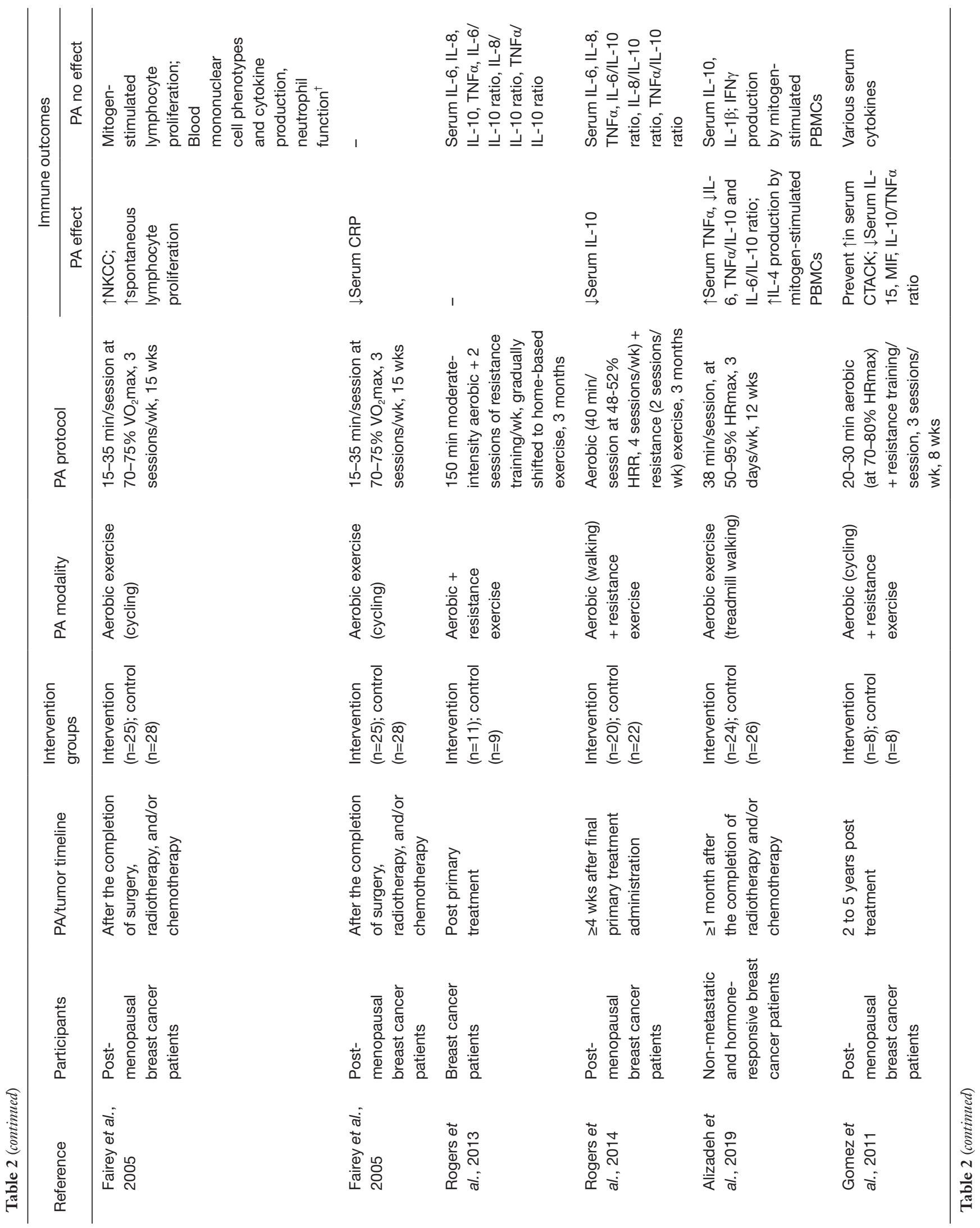




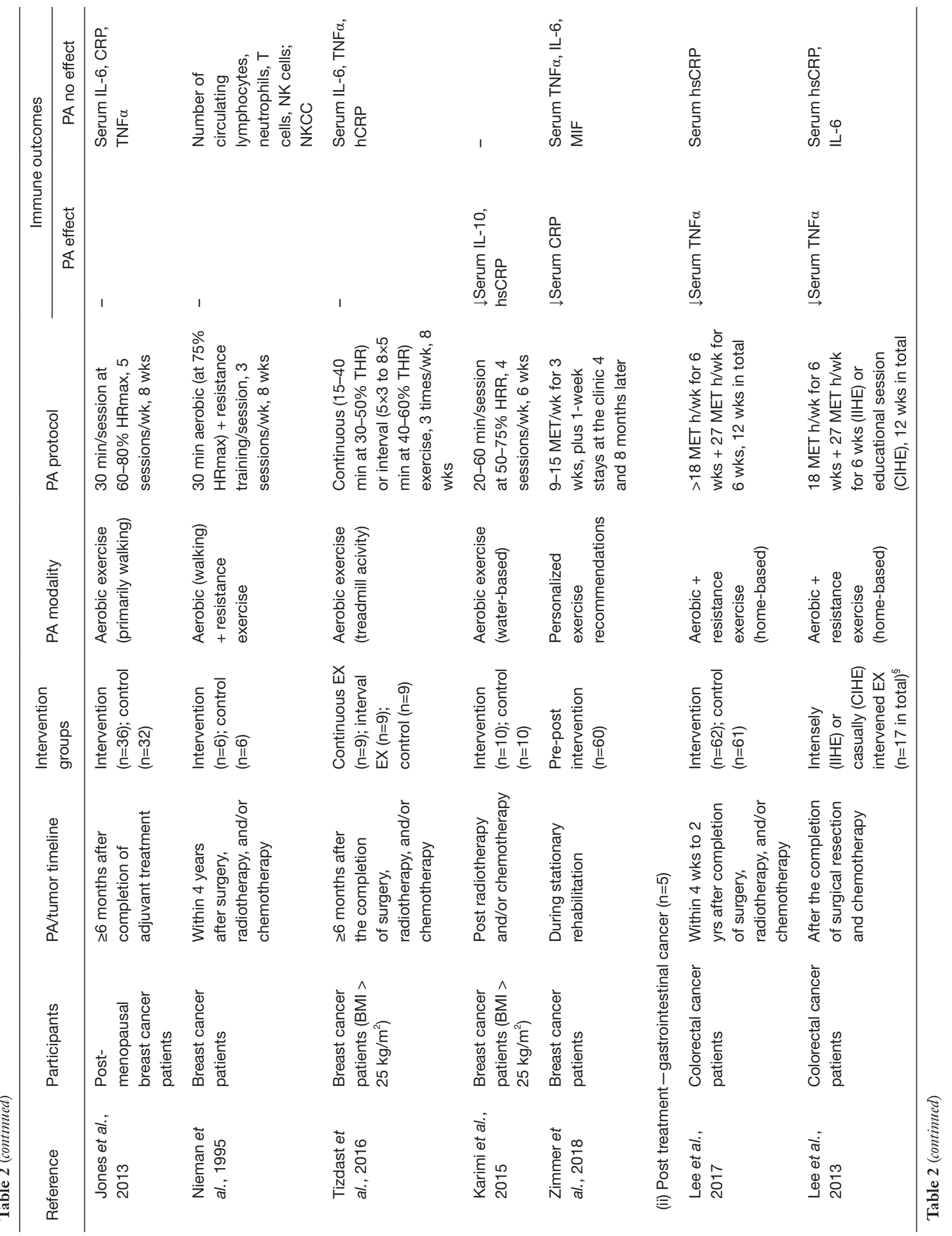




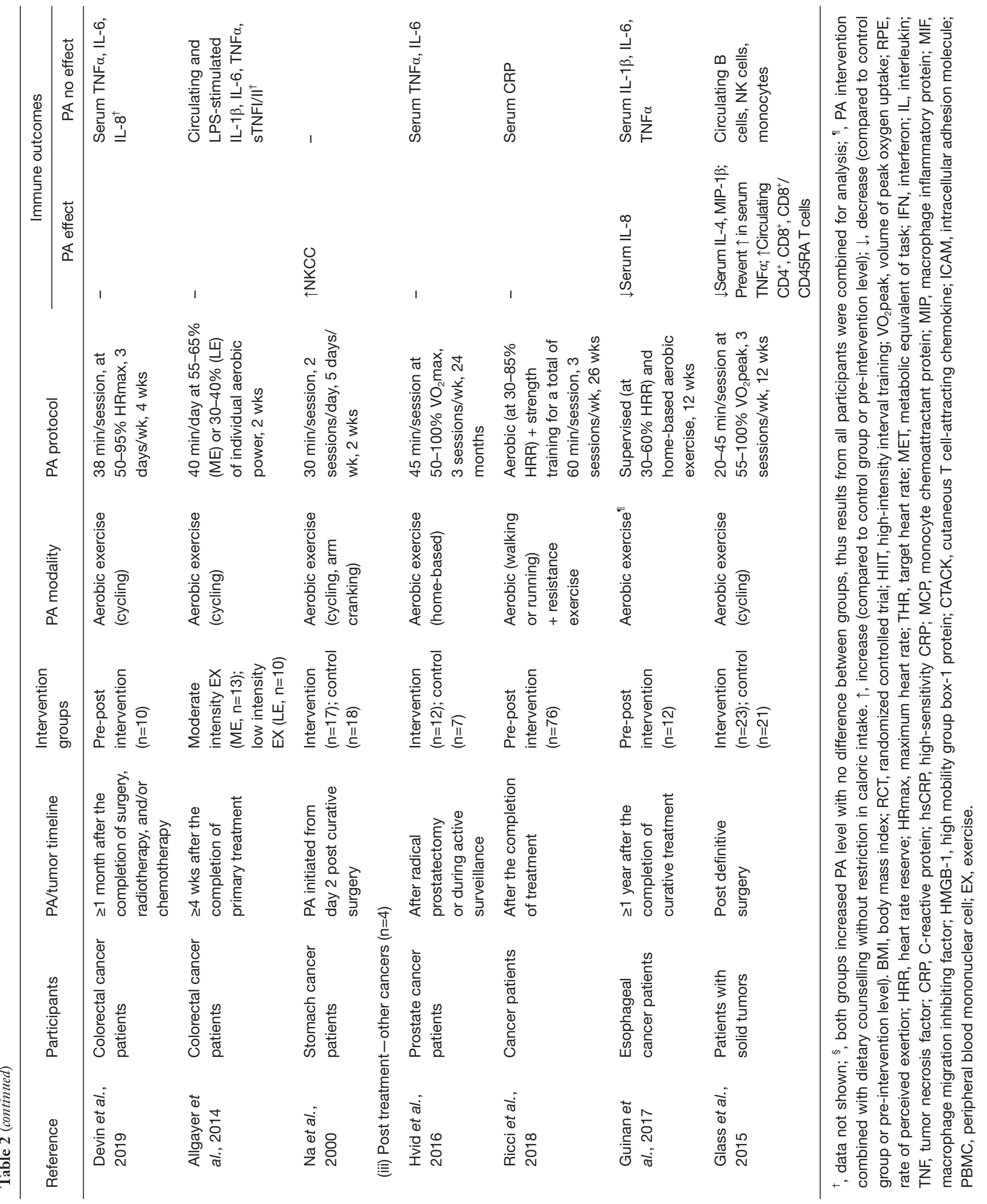


was also found, while no change was observed in tumorinfiltrating $\mathrm{CD}^{+}$or $\mathrm{CD}^{+}{ }^{+} \mathrm{T}$ cells or macrophages.

\section{Effects of ER on cancer immune outcomes}

\section{Preclinical findings}

Twenty-two studies investigated the effect of ER interventions on cancer immune outcomes using preclinical cancer models (Table 3). Two additional studies $(120,121)$ investigating the effects of caloric restriction mimetics (CRMs) on cancer immune outcomes were also included in Table 3. Compared to preclinical studies using PA interventions, the ER studies comprised a more diverse group of cancer types, including breast $(\mathrm{n}=5,23 \%)(45,122-125)$, gastrointestinal $(\mathrm{n}=5,23 \%)(126-130)$, lung $(\mathrm{n}=2,9 \%)$ $(131,132)$, liver $(\mathrm{n}=2,9 \%)(133,134)$, pancreatic $(\mathrm{n}=2$, $9 \%)(135,136)$ and several other cancer types $(n=6,27 \%)$ (137-142). ER regimens used can be divided into two broad categories: continuous ER and intermittent fasting. Continuous ER was mostly given as a $30-40 \%$ reduction in caloric intake, except for two studies where a $5 \%$ (131) or $10 \%$ (45) reduction in caloric intake was applied, respectively. Intermittent fasting was commonly applied as periodic fasting and refeeding, with the fasting interval ranging from several hours per day to several days per week [different types of ER regimens are reviewed in (143)]. Notably, four studies investigated the effect of ER in comparison to ad libitum fed control and obese mice on cancer immune outcomes $(128,136-138)$. In four additional studies, mice were fed a high fat diet to induce obesity, and an ER regimen was implemented to evaluate the effect of ER-induced weight loss in obesity on tumor and immune outcomes $(125,130-132)$. Despite the heterogeneity in study designs, 21 of 22 studies reported positive effects of ER on tumor outcomes including reduced tumor incidence, tumor growth, metastases, and improved survival independent of starting body weight.

Similar to preclinical PA studies, immune outcomes in the preclinical ER studies were commonly assessed in the tumor, spleen and blood. In the spleen, the percentage of $T$ cells was increased in three studies $(130,136,139)$, and $\mathrm{T}$ cell proliferation and CTL activity were increased in two studies $(45,139)$ and one study $(139)$, respectively. The percentage of NK cells was unchanged in one study (124), while NK cell cytotoxicity was increased in two studies $(124,140)$ and reduced in one study (139). The percentage and/or number of MDSCs was also reduced in two studies $(45,136)$. The number of total circulating leukocytes and lymphocytes was reduced in two studies $(133,140)$, while increased lymphocyte proliferation was found in another study (141). Among the serum cytokines evaluated, TNF $\alpha$ was reduced in one study (128) and increased in another study (140). IL-6 was reduced in two studies $(128,137)$ and unchanged in one study (127). MCP-1 was reduced in five studies $(125,131,132,135,137)$. IFN $\gamma$ was increased in one study (140) and unchanged in two studies $(127,128)$. A few studies also assessed immune outcomes in other tissue compartments. One study found an increased percentage of $\mathrm{T}$ cells and a reduced percentage of MDSCs in the TDLN (136), and another study reported an increase in the percentage of $\mathrm{T}$ cells and macrophages in the nonTDLN (130).

Among the tumor immune infiltrates, the percentage and/or number of $\mathrm{T}$ cells was increased in two studies $(45,136)$, reduced in two studies $(134,138)$, and unchanged in one study (122). The percentage and/or number of MDSCs was reduced in two studies $(45,136)$, macrophages was reduced in three studies $(129,138,142)$, and Tregs was unchanged in one study (122). Among the inflammatory cytokines within the tumor, TNF $\alpha$ was increased in one study (126) and reduced in another study (138), IL-6 was reduced in two studies $(126,138)$ and unchanged in one study (123), and IL-1 $\beta(126,138)$ and MCP-1 $(126,135)$ were each reduced in two studies. In addition, two studies reported changes in multiple immune and inflammatory pathways within the TME $(45,134)$.

Apart from the aforementioned studies using dietary ER interventions, two studies investigating the effects of CRMs on cancer immune outcomes were also identified. In one study using an experimental metastasis model (120), CRM administration resulted in a reduction in lung metastasis, concurrently with favorable changes in the immune cell populations and cytotoxic activity in the lung. In the other study (121), CRM had no effect on tumor growth or tumorinfiltrating Tregs when used alone, while it improved the efficacy of chemotherapy with enhanced anti-cancer immunosurveillance.

\section{Clinical findings}

Only six clinical studies were identified that investigated the effect of ER on tumor immune outcomes (Table 4). All six studies were conducted in cancer patients with overweight or obesity, and weight loss interventions included the combination of PA and ER. Five out of the six studies (144-148) were conducted in breast cancer patients, and one study (149) recruited patients of a mix of cancer types. 


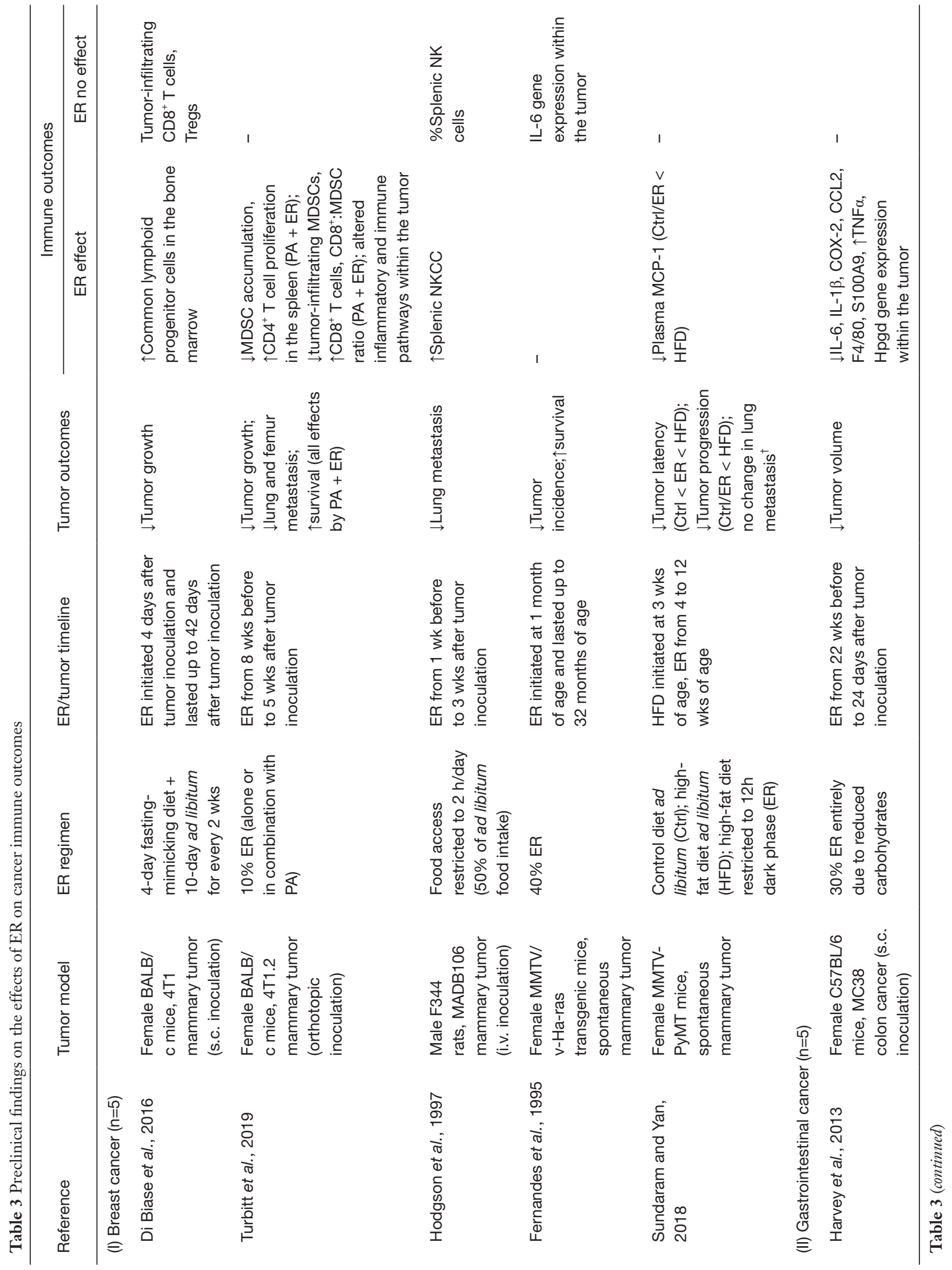




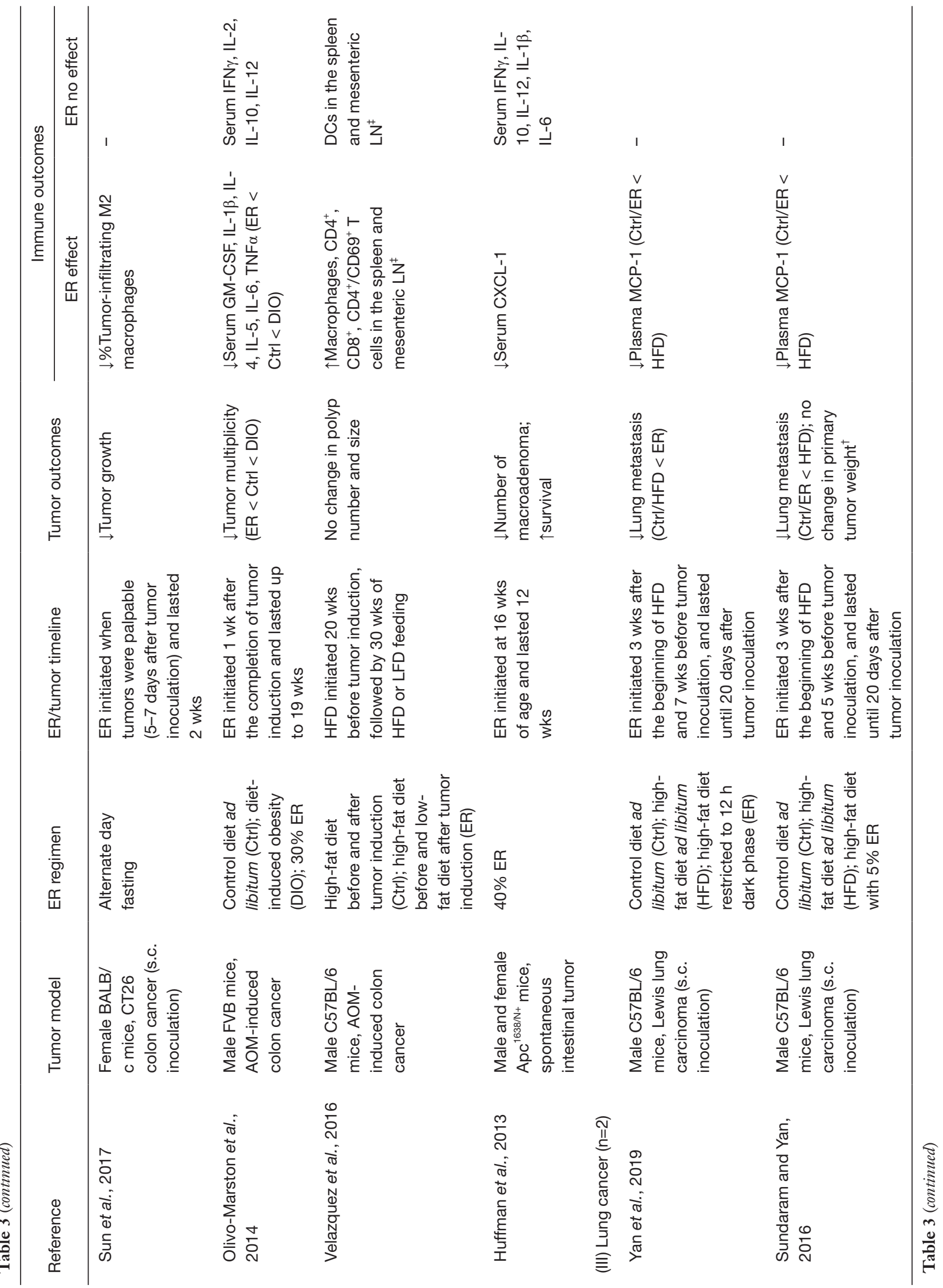




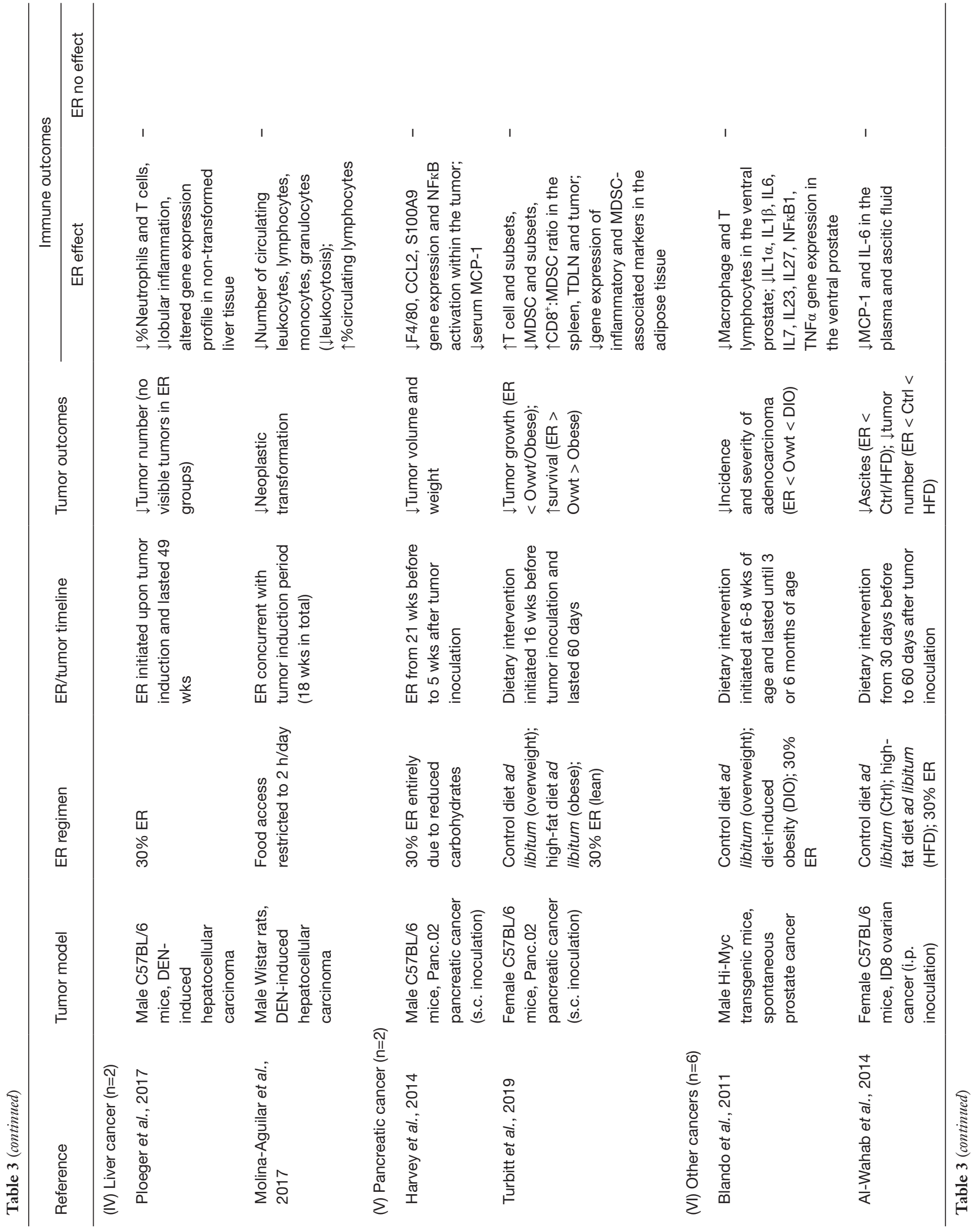




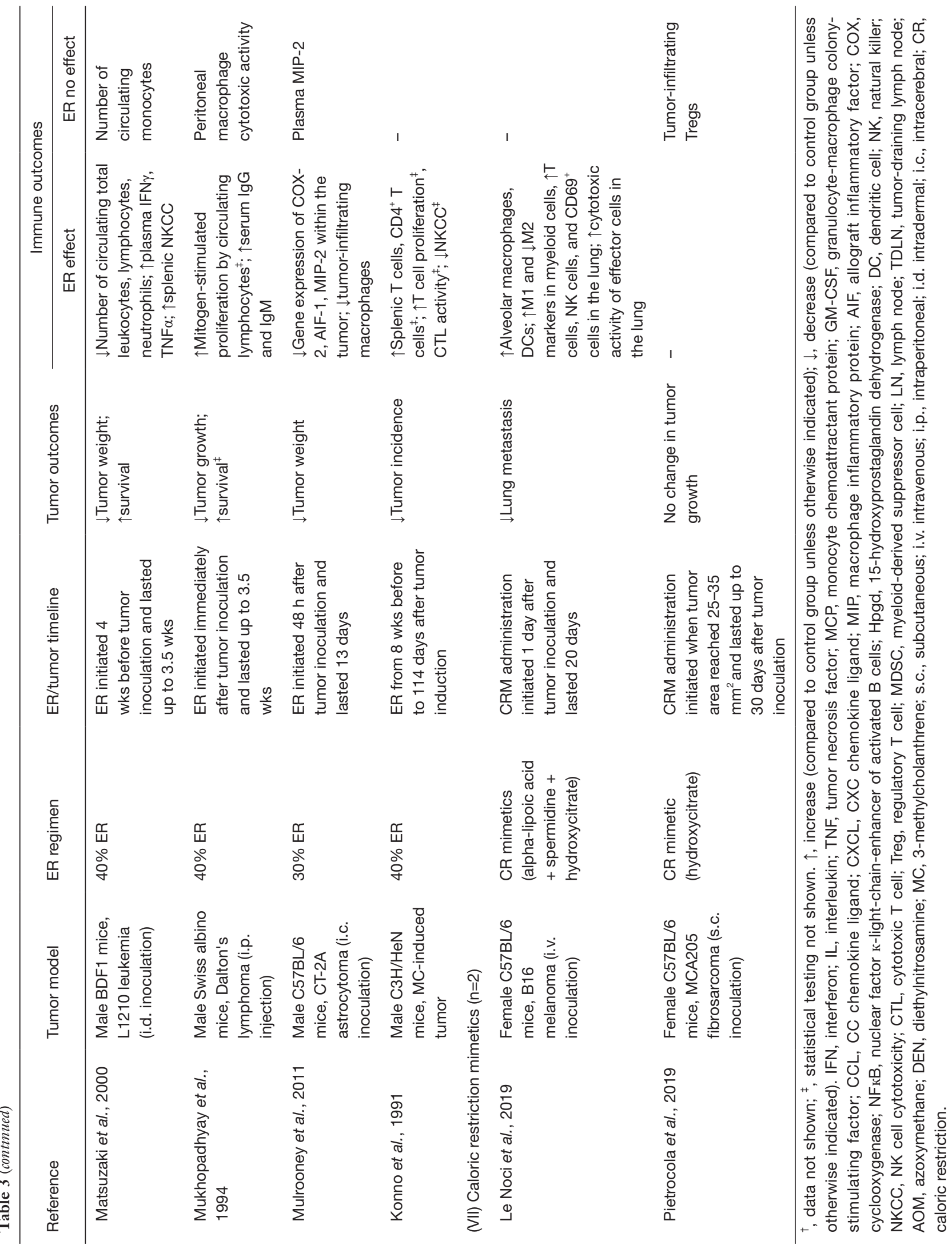


Table 4 Clinical findings on the effects of weight loss (by PA+ER) on cancer immune outcomes

\begin{tabular}{|c|c|c|c|c|c|c|c|c|}
\hline \multirow[b]{2}{*}{ Reference } & \multirow{2}{*}{ Participants } & \multirow{2}{*}{$\begin{array}{l}\text { Intervention/ } \\
\text { tumor timeline }\end{array}$} & \multirow{2}{*}{$\begin{array}{l}\text { Intervention } \\
\text { groups }\end{array}$} & \multicolumn{3}{|c|}{ Weight loss intervention protocol } & \multicolumn{2}{|c|}{ Immune outcomes } \\
\hline & & & & $\begin{array}{l}\text { PA } \\
\text { intervention }\end{array}$ & ER intervention & Length & $P A+E R$ effect & $\begin{array}{l}\mathrm{PA}+\mathrm{ER} \text { no } \\
\text { effect }\end{array}$ \\
\hline $\begin{array}{l}\text { Demark- } \\
\text { Wahnefried et } \\
\text { al., } 2019\end{array}$ & $\begin{array}{l}\text { Breast cancer } \\
\text { patients (BMI } \\
\left.\geq 25 \mathrm{~kg} / \mathrm{m}^{2}\right)\end{array}$ & Before surgery & $\begin{array}{l}\text { Intervention } \\
(n=17) \\
\text { control } \\
(n=15)\end{array}$ & $\begin{array}{l}\text { Supervised } \\
(1-2 \text { sessions/ } \\
\text { wk) and } \\
\text { home-based } \\
\text { aerobic } \\
\text { exercise }\end{array}$ & $\begin{array}{l}\text { Dietary counseling } \\
\text { on ER to achieve } \\
\text { an energy deficit of } \\
750-1,000 \mathrm{kcal} / \text { day }\end{array}$ & $\begin{array}{l}30 \text { days } \\
\text { on } \\
\text { average }\end{array}$ & $\begin{array}{l}\uparrow \text { Serum TNF } \alpha \text {; } \\
\uparrow T N F \alpha \text { nuclear } \\
\text { staining, } \\
\uparrow \text { gene } \\
\text { expression of } \\
\text { IL-1 } 1 \beta, \text { CX3CL1 } \\
\text { and CXCL1 in } \\
\text { the tumor }\end{array}$ & Serum IL-6 \\
\hline $\begin{array}{l}\text { Pakiz et al., } \\
2011\end{array}$ & $\begin{array}{l}\text { Breast cancer } \\
\text { patients (BMI } \\
\left.\geq 25 \mathrm{~kg} / \mathrm{m}^{2}\right)\end{array}$ & $\begin{array}{l}\text { After the } \\
\text { completion } \\
\text { of surgery, } \\
\text { radiotherapy, } \\
\text { and/or } \\
\text { chemotherapy }\end{array}$ & $\begin{array}{l}\text { Pre-post } \\
\text { intervention } \\
(n=44)\end{array}$ & $\begin{array}{l}\text { PA guidance } \\
\text { to achieve } \\
\geq 1 \mathrm{~h} / \text { day of } \\
\text { moderate- } \\
\text { intensity } \\
\text { aerobic } \\
\text { exercise }\end{array}$ & $\begin{array}{l}\text { Dietary guidance } \\
\text { on ER to achieve } \\
\text { an energy deficit of } \\
500-1,000 \mathrm{kcal} / \text { day }\end{array}$ & $\begin{array}{l}12 \\
\text { months }\end{array}$ & $\downarrow$ Serum IL-6 & $\begin{array}{l}\text { Serum TNF } \alpha \text {, } \\
\text { IL-8 }\end{array}$ \\
\hline $\begin{array}{l}\text { Saxton et al., } \\
2014\end{array}$ & $\begin{array}{l}\text { Breast cancer } \\
\text { patients (BMI } \\
\left.>25 \mathrm{~kg} / \mathrm{m}^{2}\right)\end{array}$ & $\begin{array}{l}\text { Within } \\
3-18 \text { months } \\
\text { after the } \\
\text { completion } \\
\text { of surgery, } \\
\text { radiotherapy, } \\
\text { and/or } \\
\text { chemotherapy }\end{array}$ & $\begin{array}{l}\text { Intervention } \\
(n=44) \\
\text { control } \\
(n=41)\end{array}$ & $\begin{array}{l}30 \text { min } \\
\text { aerobic (65- } \\
85 \% \text { HRmax) } \\
+10-15 \text { min } \\
\text { resistance } \\
\text { exercise/ } \\
\text { session, } 3 \\
\text { sessions/wk }\end{array}$ & $\begin{array}{l}\text { Individualized } \\
\text { hypocaloric healthy } \\
\text { eating program to } \\
\text { achieve an energy } \\
\text { deficit of } 600 \mathrm{kcal} / \\
\text { day }\end{array}$ & 24 wks & $\begin{array}{l}\uparrow \text { Prevent in } \\
\text { circulating } \\
\text { leukocytes, } \\
\text { neutrophils, } \\
\text { lymphocytes, } \\
\text { CD4 }{ }^{+} \text {and } \\
\text { CD8 }{ }^{+} T \text { cells }\end{array}$ & $\begin{array}{l}\text { Circulating } \\
\text { monocytes, } \\
\text { NK cells; } \\
\text { serum IL-6, } \\
\text { TNF } \alpha \text {; NKCC, } \\
\text { mitogen- } \\
\text { stimulated } \\
\text { lymphocyte } \\
\text { proliferation }\end{array}$ \\
\hline $\begin{array}{l}\text { Campbell } \\
\text { et al., } 2012\end{array}$ & $\begin{array}{l}\text { Breast cancer } \\
\text { patients }(\mathrm{BMI} \\
\left.25-35 \mathrm{~kg} / \mathrm{m}^{2}\right)\end{array}$ & $\begin{array}{l}\geq 3 \text { months after } \\
\text { the completion } \\
\text { of adjuvant } \\
\text { treatment }\end{array}$ & $\begin{array}{l}\text { Pre-post } \\
\text { intervention } \\
(n=14)\end{array}$ & $\begin{array}{l}\text { Supervised } \\
\text { and home- } \\
\text { based } \\
\text { aerobic } \\
\text { exercise to } \\
\text { achieve } 150 \\
\text { min/wk of } \\
\text { moderate- } \\
\text { vigorous PA }\end{array}$ & $\begin{array}{l}\text { Dietary sessions } \\
\text { and individually } \\
\text { prescribed ER to } \\
\text { achieve a } 7 \% \text { loss of } \\
\text { baseline body weight }\end{array}$ & 24 wks & - & Serum CRP \\
\hline $\begin{array}{l}\text { Swisher et al., } \\
2015\end{array}$ & $\begin{array}{l}\text { Breast cancer } \\
\text { patients (BMI } \\
\left.>25 \mathrm{~kg} / \mathrm{m}^{2}\right)\end{array}$ & $\begin{array}{l}\geq 3 \text { months after } \\
\text { the completion } \\
\text { of active } \\
\text { treatment }\end{array}$ & $\begin{array}{l}\text { Intervention } \\
(n=13) \\
\text { control } \\
(n=10)\end{array}$ & $\begin{array}{l}\text { Aerobic } \\
\text { exercise (30 } \\
\text { min/session } \\
\text { at } 60-75 \% \\
\text { HRmax, } 5 \\
\text { sessions/wk) }\end{array}$ & $\begin{array}{l}\text { Dietary counseling } \\
\text { to achieve } 200 \mathrm{kcal} / \\
\text { wk reduction in fat } \\
\text { calories }\end{array}$ & 16 wks & - & $\begin{array}{l}\text { Serum CRP, } \\
\text { IL-6, TNF } \alpha\end{array}$ \\
\hline $\begin{array}{l}\text { Brown et al., } \\
2018\end{array}$ & $\begin{array}{l}\text { Patients of } \\
\text { hematologic } \\
\text { malignancies } \\
\text { and solid } \\
\text { tumors }(\mathrm{BMI} \\
\left.>25 \mathrm{~kg} / \mathrm{m}^{2}\right)\end{array}$ & $\begin{array}{l}\geq 1 \text { month after } \\
\text { the completion } \\
\text { of surgery, } \\
\text { radiotherapy, } \\
\text { and/or } \\
\text { chemotherapy }\end{array}$ & $\begin{array}{l}\text { Intervention } \\
(n=30) \\
\text { control } \\
(n=30)\end{array}$ & $\begin{array}{l}\text { Supervised } \\
\text { aerobic } \\
\text { exercise to } \\
\text { achieve 150- } \\
200 \text { min/wk } \\
\text { of moderate- } \\
\text { intensity PA }\end{array}$ & $\begin{array}{l}\text { Dietary } \\
\text { recommendations to } \\
\text { achieve an energy } \\
\text { deficit of } 500-1,000 \\
\text { kcal/day }\end{array}$ & 15 wks & - & $\begin{array}{l}\text { Serum CRP, } \\
\text { IL-6 }\end{array}$ \\
\hline
\end{tabular}

$\uparrow$, increase (compared to control group or pre-intervention level); $\downarrow$, decrease (compared to control group or pre-intervention level). BMI, body mass index; HRmax, maximum heart rate; IL, interleukin; TNF, tumor necrosis factor; CXCL, CXC chemokine ligand; CX3CL, CX3C chemokine ligand; CRP, C-reactive protein; NKCC, natural killer cell cytotoxicity. 
One study (145) assessed the effect of a pre-surgical weight loss intervention on serum and intratumoral immune and inflammatory markers. The remaining five studies applied the weight loss interventions post-cancer treatment and only blood samples were analyzed.

When comparing the serum cytokine levels in the weight loss intervention group to the control, TNF $\alpha(145,147,148)$, IL-6 (145,147-149), and CRP $(148,149)$ were mainly unchanged. When comparing post-intervention to preintervention, TNFa (146) and CRP (144) were unchanged in one study, while IL-6 was reduced in one study (146). Circulating immune cells were compared between the intervention group and the control in one study (147). The weight loss intervention prevented an increase in the number of circulating lymphocytes and neutrophils over time, while no effect on monocytes, NK cell number or cytotoxicity, or lymphocyte proliferation was found after weight loss.

Immune outcomes within the tumor were assessed in one study (145). A weight loss intervention conducted prior to surgery resulted in an altered gene expression profile in the tumor, including an upregulation of multiple pathways associated with immune function, notably genes encoding IL- $1 \beta$, and the chemokines CX3CL1 and CXCL1. In addition, genes associated with cytolytic $\mathrm{CD} 56^{\mathrm{dim}} \mathrm{NK}$ cells were also positively correlated with weight loss.

\section{Discussion}

In the current study, we evaluated preclinical and clinical studies investigating the effects of PA and ER on cancer immune outcomes. To our knowledge, this is the first review to assess the existing evidence on the effects of energy balance-related interventions on host immune responses across the cancer continuum.

\section{$P A$ preclinical findings}

Abundant evidence from epidemiological studies suggest that PA is associated with reduced cancer risk, mortality and recurrence, with the strongest evidence found in breast and colon cancer (3-7). As a result, much attention has been paid to these two cancer types in both preclinical and clinical studies investigating the effect of PA interventions on cancer immune outcomes. Consistent with the findings reported in epidemiological studies, the majority of preclinical studies included in this review reported a beneficial effect of PA on tumor incidence, progression, metastasis and survival. However, existing evidence on the effect of PA on cancer immune outcomes is highly heterogeneous. A wide range of immunological parameters has been assessed from multiple tissue compartments, yet each parameter is usually assessed by a small number of studies with mixed findings.

Because PA is a systemic intervention involving multiple organ systems, changes in systemic immune responses may underlie the beneficial effects of PA on cancer. Studies evaluating splenic immunity mostly focused on NK cells, with two $(77,80)$ and three $(62,79,80)$ reports on increased NK cell percentage/number and cytotoxicity, respectively. In the circulation, a reduction in inflammatory cytokines TNFa, IL-6 and MCP-1 was observed in a few studies $(65,68,70,72,74)$, while several other studies $(58,59,68,78)$ reported no change in serum inflammatory cytokines.

The TME harbors immune cells and molecules directly interacting with the tumor cells. Alterations in these factors may have a significant impact on tumor progression. Existing evidence suggests that PA may result in an increase in anti-tumor effector cells (T cells and NK cells) $(44,45,73)$ and a reduction in pro-tumor immunosuppressive cells (Tregs and MDSCs) $(45,61,73)$ within the TME. However, two studies also reported null results for these cell types $(57,58)$. In addition, several studies found an increase in the percentage of $\mathrm{CD}^{+} / \mathrm{IFN} \gamma^{+}$cells in the TDLN (77) and enhanced lymphocyte proliferation from the non-TDLN in physically active hosts $(55,56,76)$, suggesting a PA-induced enhancement in effector cells against the tumor.

Two studies reported global changes in the gene expression profile of immune and inflammatory mediators within the TME $(44,45)$. In the B16 melanoma model, voluntary wheel running increased gene expression of both pro- and anti-inflammatory cytokines as well as NK cell markers, potentially promoting an inflammatory TME and activation of subsequent anti-tumor immune response (44). In the 4T1.2 mammary tumor model, voluntary wheel running, when combined with mild (10\%) ER, reduced the expression of chemokines important in MDSC and Treg recruitment, as well as other immune inhibitory molecules (45), including programmed death protein 1 (PD-1) and indoleamine 2,3-dioxygenase (IDO) $(150,151)$. Furthermore, both studies observed an increase in $\mathrm{T}$ cell infiltration into tumors in physically active animals. Despite the differences in these cancer models, findings from these two studies suggest that PA may be reshaping the TME to allow greater anti-tumor immune response with less immunosuppression.

It is worth noting that the interpretation of existing evidence may be confounded by the heterogeneity in 
the study design of the PA interventions, including the modality, frequency, intensity and duration of each PA session, as well as the total length of the intervention period and the window of PA intervention in relation to cancer treatment. Several studies examined the effect of PA modality, intensity or length of intervention on cancer and immune outcomes, but overall there was insufficient data to determine what intervention protocols may be the most effective in improving cancer and immune outcomes.

\section{$P A$ clinical findings}

Despite the heterogeneity in the design of PA interventions, most clinical studies reported no effect of PA on serum inflammatory cytokines and circulating immune cells. This is the case regardless of when the PA intervention occurred with respect to cancer treatment. In contrary to our findings, a recent meta-analysis by Khosravi et al. (49) reported that exercise training decreases circulating proinflammatory markers, notably CRP and TNF, in cancer survivors. However, this meta-analysis included studies performing all types of structured exercise intervention (aerobic, resistance or combined training or Tai Chi/yoga), while we focused on the effect of chronic, aerobic PA in the current study. Additionally, Khosravi et al. assessed the effects of exercise training only post-treatment in adult cancer survivors, while we included studies with cancer patients during all stages of treatment. It may be that the type of activity intervention and time since cancer treatment are important variables influencing the relationship between activity and circulating cytokines.

In humans, the effect of PA on immune outcomes within the tumor has not been explored in many studies. Only one study evaluated a pre-surgical PA intervention in breast cancer patients and demonstrated that PA resulted in an upregulation in multiple pathways involved in immune cell function and inflammatory signaling within the TME (94). These results are consistent with preclinical findings and suggest that PA may have a significant impact on the immune response within the tumor. However, additional studies are needed to confirm these findings.

\section{ER preclinical findings}

The effect of ER on cancer outcomes has mostly been studied in preclinical cancer models. Despite the heterogeneity in study designs, the preclinical studies included in this review consistently reported beneficial effects of ER on tumor incidence, progression, metastasis and survival in normal weight hosts. Four studies investigated the effect of ER, a control diet fed ad libitum and feeding a high fat diet to induce obesity in different cancer models $(128,136-138)$. All demonstrated that tumor outcomes are improved by ER and exacerbated by obesity. An additional four studies $(125,130-132)$ evaluated the effect of ER in obese mice. In three of these studies $(125,131,132)$, ER reduced tumor progression or lung metastasis in obese mice to the level observed in normal weight mice. These results suggest that ER may have a beneficial effect on cancer outcomes in both normal weight and obese hosts.

Similar to the PA intervention studies, preclinical ER intervention studies have also assessed a wide variety of immunological parameters, while each parameter is usually assessed by a small number of studies with mixed findings. ER increases the percentage of splenic T cells $(130,136,139)$ and their function (proliferation and CTL activity) $(45,139)$. Splenic MDSC accumulation was also reduced in two studies $(45,136)$. In addition, serum MCP-1 was reduced in five studies $(125,131,132,135,137)$, while other circulating inflammatory cytokines were reported with mixed results.

Existing evidence suggests that ER may reduce inflammation and immunosuppression within the TME. The inflammatory cytokines IL- $1 \beta$, IL- 6 and MCP- 1 in the tumor were reduced by ER in several studies $(126,135,138)$. The percentage of tumor-infiltrating MDSCs was also reduced in two studies $(45,136)$, suggesting that ER may reduce immune suppression both systemically and within the TME. ER in combination with PA resulted in global changes in the gene expression profile within the 4T1.2 mammary tumor, notably a downregulation of an array of genes involved in immune suppression (45). Similar findings were reported in a carcinogen-induced liver cancer model, where a $30 \%$ ER prevented hepatic tumor formation while downregulating multiple pathways involved in inflammation (134). Overall, preclinical studies evaluating the effects of ER on cancer immune outcomes also present a mix of positive and null findings. Some evidences suggest that ER may prevent an immunosuppressive TME and induce favorable changes in splenic effector $v s$. immunosuppressive cells.

\section{ER clinical findings}

To date, all clinical studies applying ER interventions have been conducted in cancer patients with overweight or obesity with the purpose of weight loss. The weight 
loss intervention in all six included studies combined PA with ER, thus precluding the ability to make conclusions regarding the efficacy of each intervention alone on immune outcomes. Despite the limited number of studies, evaluation of serum inflammatory cytokines mostly resulted in null findings. This suggests that, similar to PA interventions, weight loss by the combination of PA+ER may not have a significant impact on cancer immune response in the circulation. In the study by DemarkWahnefried et al. (145), a weight loss intervention prior to surgery altered the gene expression profile within the TME, represented by an upregulation of multiple pathways associated with immune function. These results support the hypothesis that PA and ER interventions may be modulating the immune response within the TME, but additional studies are needed to examine this issue.

ER regimens may not be tolerated or feasible for cancer patients. Thus, CRMs have been explored. CRMs mimic the biochemical effects of nutrient deprivation without drastic changes in the calorie content of the diets, and have anti-tumor effects in several preclinical studies (152). While most studies attribute their beneficial effects to the induction of autophagy, emerging evidence also suggests that CRMs may improve anti-cancer immune surveillance when used alone or in combination with chemotherapy $(120,121)$. In the current preclinical evidence base, intermittent fasting is as effective as chronic ER in improving tumor and immune outcomes, and may prove to be another alternative to prolonged dietary ER in cancer patients. Using a preclinical cancer model, we have shown that the combination of PA and $10 \% \mathrm{ER}$ is as effective as a single $30-40 \%$ ER intervention in reducing tumor progression and improving survival. Furthermore, the combination of PA and mild ER induces beneficial changes in multiple immune mechanisms to a greater extent than either intervention alone (45). Thus, by combining lifestyle interventions such as PA with ER, we may be able to use a less severe ER regimen to improve cancer outcomes.

One limitation of the current review is that the included studies are highly heterogeneous in terms of cancer type, animal model or human participant characteristics, and the PA or ER protocol. There are also limitations inherent to the included human studies. A number of the human studies are exploratory trials with small sample size, and some are not powered for immune outcome measures. In addition, patient adherence to the PA and/or ER interventions varied from $66-98 \%$ in the included studies. Thus, limited conclusions can be made as to the role of PA and ER on cancer-related immune outcomes.

\section{Conclusions and future directions}

There is mounting interest in the effect of energy balancerelated lifestyle interventions on cancer immune responses. Preclinical studies clearly suggest a beneficial effect of PA and ER on tumor outcomes. However, little is known about which immune mechanisms may be the most important contributor to the improved tumor outcomes observed in response to either PA or ER interventions. Further mechanistic studies are warranted to better understand the relationship between energy balance-related interventions, improved cancer outcomes, and host immune responses. To this end, we recommend the use of more clinically relevant cancer models, including orthotopic tumor transplantation and spontaneous tumor development in geneticallyengineered animals. The impact of different PA and ER protocols should also be carefully evaluated to inform clinical application. As such, standardized reporting of the intervention protocols [such as those proposed by Ashcraft et al. (32)] is encouraged.

Existing clinical evidence suggest against a significant impact of PA or ER on circulating inflammatory cytokines, while emerging evidence from both preclinical and clinical studies suggest that PA and ER may significantly alter the immune and inflammatory milieu within the TME. Future studies that examine the immunological changes within the TME in response to PA and/or ER may provide valuable insight into the relevant immune pathways that may be altered. In addition, previous clinical studies have primarily assessed the effect of PA and ER interventions post-cancer treatment. Additional studies are needed to evaluate the effect of PA and ER performed prior to, or concurrently with cancer treatment to determine if a critical window exists where energy balance-related interventions may result in maximal benefit. Because PA and ER target the two components of the energy balance equation (energy expenditure and energy intake, respectively), it would also be interesting to assess if any additive or synergistic effects exist between PA and ER on cancer immune regulation. Finally, several studies demonstrate that PA and ER may enhance the efficacy of chemotherapy $(121,122,153)$, while no studies, to our knowledge, have assessed the effect of PA and/or ER on immunotherapy outcomes. Future studies are needed to determine if ER and/or PA could be used in combination with standard or experimental therapies to improve clinical outcomes. 


\section{Acknowledgments}

Funding: YX was supported by a T32 Training Program (T32GM108563) Research training in Physiological Adaptations to Stress while at The Pennsylvania State University.

\section{Footnote}

Provenance and peer review: This article was commissioned by the Guest Editor (Nathan A. Berger) for the series "Energy Balance, Aging, Obesity, and Cancer" published in Translational Cancer Research. The article was sent for external peer review organized by the Guest Editor and editorial office.

Conflicts of Interest: Both authors have completed the ICMJE uniform disclosure form (available at http://dx.doi. org/10.21037/tcr.2020.03.38). The series "Energy Balance, Aging, Obesity, and Cancer" was commissioned by the editorial office without any funding or sponsorship. The authors have no other conflicts of interest to declare.

Ethical Statement: The authors are accountable for all aspects of the work in ensuring that questions related to the accuracy or integrity of any part of the work are appropriately investigated and resolved.

Open Access Statement: This is an Open Access article distributed in accordance with the Creative Commons Attribution-NonCommercial-NoDerivs 4.0 International License (CC BY-NC-ND 4.0), which permits the noncommercial replication and distribution of the article with the strict proviso that no changes or edits are made and the original work is properly cited (including links to both the formal publication through the relevant DOI and the license). See: https://creativecommons.org/licenses/bync-nd $/ 4.0 \%$.

\section{References}

1. American Cancer Society. Cancer Facts \& Figures 2019.

2. Fulop T, Kotb R, Fortin CF, et al. Potential role of immunosenescence in cancer development. Ann N Y Acad Sci 2010;1197:158-65.

3. World Cancer Research Fund/American Institute for Cancer Research. Continuous update project expert report 2018. Diet, nutrition, physical activity and cancer. 2018.
4. Rezende LFM, Sa TH, Markozannes G, et al. Physical activity and cancer: an umbrella review of the literature including 22 major anatomical sites and 770000 cancer cases. Br J Sports Med 2018;52:826-33.

5. van Zutphen M, Kampman E, Giovannucci EL, et al. Lifestyle after Colorectal Cancer Diagnosis in Relation to Survival and Recurrence: A Review of the Literature. Curr Colorectal Cancer Rep 2017;13:370-401.

6. Peterson LL, Ligibel JA. Physical Activity and Breast Cancer: an Opportunity to Improve Outcomes. Curr Oncol Rep 2018;20:50.

7. Cormie P, Zopf EM, Zhang X, et al. The Impact of Exercise on Cancer Mortality, Recurrence, and TreatmentRelated Adverse Effects. Epidemiol Rev 2017;39:71-92.

8. Lauby-Secretan B, Scoccianti C, Loomis D, et al. Body Fatness and Cancer--Viewpoint of the IARC Working Group. N Engl J Med 2016;375:794-8.

9. Lee DH, Giovannucci EL. The Obesity Paradox in Cancer: Epidemiologic Insights and Perspectives. Curr Nutr Rep 2019;8:175-81.

10. Protani MM, Nagle CM, Webb PM. Obesity and ovarian cancer survival: a systematic review and meta-analysis. Cancer Prev Res (Phila) 2012;5:901-10.

11. Secord AA, Hasselblad V, Von Gruenigen VE, et al. Body mass index and mortality in endometrial cancer: A systematic review and meta-analysis. Gynecol Oncol 2016;140:184-90.

12. Chan DS, Vieira AR, Aune D, et al. Body mass index and survival in women with breast cancer-systematic literature review and meta-analysis of 82 follow-up studies. Ann Oncol 2014;25:1901-14.

13. Jiralerspong S, Goodwin PJ. Obesity and Breast Cancer Prognosis: Evidence, Challenges, and Opportunities. J Clin Oncol 2016;34:4203-16.

14. Luo J, Hendryx M, Manson JE, et al. Intentional Weight Loss and Obesity-Related Cancer Risk. JNCI Cancer Spectr 2019;3:pkz054.

15. Christou NV, Lieberman M, Sampalis F, et al. Bariatric surgery reduces cancer risk in morbidly obese patients. Surg Obes Relat Dis 2008;4:691-5.

16. McCawley GM, Ferriss JS, Geffel D, et al. Cancer in obese women: potential protective impact of bariatric surgery. J Am Coll Surg 2009;208:1093-8.

17. Adams TD, Stroup AM, Gress RE, et al. Cancer incidence and mortality after gastric bypass surgery. Obesity (Silver Spring) 2009;17:796-802.

18. Sjöström L, Gummesson A, Sjostrom CD, et al. Effects of bariatric surgery on cancer incidence in obese 
patients in Sweden (Swedish Obese Subjects Study): a prospective, controlled intervention trial. Lancet Oncol 2009;10:653-62.

19. Maret-Ouda J, Tao W, Mattsson F, et al. Esophageal adenocarcinoma after obesity surgery in a populationbased cohort study. Surg Obes Relat Dis 2017;13:28-34.

20. Schauer DP, Feigelson HS, Koebnick C, et al. Association Between Weight Loss and the Risk of Cancer after Bariatric Surgery. Obesity (Silver Spring) 2017;25 Suppl 2:S52-S57.

21. Eliassen AH, Colditz GA, Rosner B, et al. Adult weight change and risk of postmenopausal breast cancer. JAMA 2006;296:193-201.

22. Teras LR, Patel AV, Wang M, et al. Sustained weight loss and risk of breast cancer in women $>/=50$ years: a pooled analysis of prospective data. J Natl Cancer Inst 2020;112:929-37.

23. Schauer DP, Feigelson HS, Koebnick C, et al. Bariatric Surgery and the Risk of Cancer in a Large Multisite Cohort. Ann Surg 2019;269:95-101.

24. Teras LR, Goodman M, Patel AV, et al. Weight loss and postmenopausal breast cancer in a prospective cohort of overweight and obese US women. Cancer Causes Control 2011;22:573-9.

25. Hursting SD, Lavigne JA, Berrigan D, et al. Calorie restriction, aging, and cancer prevention: mechanisms of action and applicability to humans. Annu Rev Med 2003;54:131-52.

26. Pifferi F, Aujard F. Caloric restriction, longevity and aging: Recent contributions from human and non-human primate studies. Prog Neuropsychopharmacol Biol Psychiatry 2019;95:109702.

27. Longo VD, Fontana L. Calorie restriction and cancer prevention: metabolic and molecular mechanisms. Trends Pharmacol Sci 2010;31:89-98.

28. Speakman JR, Mitchell SE. Caloric restriction. Mol Aspects Med 2011;32:159-221.

29. Rickman AD, Williamson DA, Martin CK, et al. The CALERIE Study: design and methods of an innovative $25 \%$ caloric restriction intervention. Contemp Clin Trials 2011;32:874-81.

30. Das SK, Roberts SB, Bhapkar MV, et al. Body-composition changes in the Comprehensive Assessment of Long-term Effects of Reducing Intake of Energy (CALERIE)-2 study: a 2-y randomized controlled trial of calorie restriction in nonobese humans. Am J Clin Nutr 2017;105:913-27.

31. Kraus WE, Bhapkar M, Huffman KM, et al. 2 years of calorie restriction and cardiometabolic risk (CALERIE): exploratory outcomes of a multicentre, phase 2, randomised controlled trial. Lancet Diabetes Endocrinol 2019;7:673-83.

32. Ashcraft KA, Peace RM, Betof AS, et al. Efficacy and Mechanisms of Aerobic Exercise on Cancer Initiation, Progression, and Metastasis: A Critical Systematic Review of In Vivo Preclinical Data. Cancer Res 2016;76:4032-50.

33. Zhang X, Ashcraft KA, Betof Warner A, et al. Can Exercise-Induced Modulation of the Tumor Physiologic Microenvironment Improve Antitumor Immunity? Cancer Res 2019;79:2447-56.

34. Hursting SD, Dunlap SM, Ford NA, et al. Calorie restriction and cancer prevention: a mechanistic perspective. Cancer Metab 2013;1:10.

35. Friedenreich CM. Physical activity and breast cancer: review of the epidemiologic evidence and biologic mechanisms. Recent Results Cancer Res 2011;188:125-39.

36. McTiernan A. Mechanisms linking physical activity with cancer. Nat Rev Cancer 2008;8:205-11.

37. Ostrand-Rosenberg S. Immune surveillance: a balance between protumor and antitumor immunity. Curr Opin Genet Dev 2008;18:11-8.

38. Swann JB, Smyth MJ. Immune surveillance of tumors. J Clin Invest 2007;117:1137-46.

39. Rogers CJ, Berrigan D, Zaharoff DA, et al. Energy restriction and exercise differentially enhance components of systemic and mucosal immunity in mice. J Nutr 2008;138:115-22.

40. Rogers CJ, Zaharoff DA, Hance KW, et al. Exercise enhances vaccine-induced antigen-specific $\mathrm{T}$ cell responses. Vaccine 2008;26:5407-15.

41. Walsh NP, Gleeson M, Shephard RJ, et al. Position statement. Part one: Immune function and exercise. Exerc Immunol Rev 2011;17:6-63.

42. Simpson RJ, Kunz H, Agha N, et al. Exercise and the Regulation of Immune Functions. Prog Mol Biol Transl Sci 2015;135:355-80.

43. Turner JE, Brum PC. Does Regular Exercise Counter T Cell Immunosenescence Reducing the Risk of Developing Cancer and Promoting Successful Treatment of Malignancies? Oxid Med Cell Longev 2017;2017:4234765.

44. Pedersen L, Idorn M, Olofsson GH, et al. Voluntary Running Suppresses Tumor Growth through Epinephrineand IL-6-Dependent NK Cell Mobilization and Redistribution. Cell Metab 2016;23:554-62.

45. Turbitt WJ, Xu Y, Sosnoski DM, et al. Physical Activity Plus Energy Restriction Prevents 4T1.2 Mammary Tumor Progression, MDSC Accumulation, and an 
Immunosuppressive Tumor Microenvironment. Cancer Prev Res (Phila) 2019;12:493-506.

46. Dixit VD. Adipose-immune interactions during obesity and caloric restriction: reciprocal mechanisms regulating immunity and health span. J Leukoc Biol 2008;84:882-92.

47. Nikolich-Zugich J, Messaoudi I. Mice and flies and monkeys too: caloric restriction rejuvenates the aging immune system of non-human primates. Exp Gerontol 2005;40:884-93.

48. Hojman P. Exercise protects from cancer through regulation of immune function and inflammation. Biochem Soc Trans 2017;45:905-11.

49. Khosravi N, Stoner L, Farajivafa V, et al. Exercise training, circulating cytokine levels and immune function in cancer survivors: A meta-analysis. Brain Behav Immun 2019;81:92-104.

50. Koelwyn GJ, Wennerberg E, Demaria S, et al. Exercise in Regulation of Inflammation-Immune Axis Function in Cancer Initiation and Progression. Oncology (Williston Park) 2015;29:908-20, 22.

51. Kruijsen-Jaarsma M, Revesz D, Bierings MB, et al. Effects of exercise on immune function in patients with cancer: a systematic review. Exerc Immunol Rev 2013;19:120-43.

52. Meynet O, Ricci JE. Caloric restriction and cancer: molecular mechanisms and clinical implications. Trends Mol Med 2014;20:419-27.

53. Liberati A, Altman DG, Tetzlaff J, et al. The PRISMA statement for reporting systematic reviews and meta-analyses of studies that evaluate health care interventions: explanation and elaboration. J Clin Epidemiol 2009;62:e1-34.

54. Almeida PW, Gomes-Filho A, Ferreira AJ, et al. Swim training suppresses tumor growth in mice. J Appl Physiol (1985) 2009;107:261-5.

55. Bacurau AV, Belmonte MA, Navarro F, et al. Effect of a high-intensity exercise training on the metabolism and function of macrophages and lymphocytes of walker 256 tumor bearing rats. Exp Biol Med (Maywood) 2007;232:1289-99.

56. Bacurau RF, Belmonte MA, Seelaender MC, et al. Effect of a moderate intensity exercise training protocol on the metabolism of macrophages and lymphocytes of tumourbearing rats. Cell Biochem Funct 2000;18:249-58.

57. Bianco TM, Abdalla DR, Desiderio CS, et al. The influence of physical activity in the anti-tumor immune response in experimental breast tumor. Immunology Letters 2017;190:148-58.

58. Buss LA, Dachs GU. Voluntary exercise slows breast tumor establishment and reduces tumor hypoxia in ApoE(/-) mice. J Appl Physiol (1985) 2018;124:938-49.

59. Faustino-Rocha AI, Gama A, Oliveira PA, et al. Effects of lifelong exercise training on mammary tumorigenesis induced by MNU in female Sprague-Dawley rats. Clin Exp Med 2017;17:151-60.

60. Goh J, Tsai J, Bammler TK, et al. Exercise training in transgenic mice is associated with attenuation of early breast cancer growth in a dose-dependent manner. PLoS One 2013;8:e80123.

61. Hagar A, Wang Z, Koyama S, et al. Endurance training slows breast tumor growth in mice by suppressing Treg cells recruitment to tumors. BMC Cancer 2019;19:536.

62. Hoffman-Goetz L, May KM, Arumugam Y. Exercise training and mouse mammary tumour metastasis. Anticancer Res 1994;14:2627-31.

63. Khori V, Shalamzari SA, Isanejad A, et al. Effects of exercise training together with tamoxifen in reducing mammary tumor burden in mice: Possible underlying pathway of miR-21. European Journal of Pharmacology 2015;765:179-87.

64. Molanouri Shamsi M, Chekachak S, Soudi S, et al. Effects of exercise training and supplementation with selenium nanoparticle on T-helper 1 and 2 and cytokine levels in tumor tissue of mice bearing the $4 \mathrm{~T} 1$ mammary carcinoma. Nutrition 2019;57:141-7.

65. Murphy EA, Davis JM, Barrilleaux TL, et al. Benefits of exercise training on breast cancer progression and inflammation in C3(1)SV40Tag mice. Cytokine 2011;55:274-9.

66. Sáez MC, Barriga C, Garcia JJ, et al. Exercise-induced stress enhances mammary tumor growth in rats: beneficial effect of the hormone melatonin. Mol Cell Biochem 2007;294:19-24.

67. Shalamzari SA, Agha-Alinejad H, Alizadeh S, et al. The effect of exercise training on the level of tissue IL-6 and vascular endothelial growth factor in breast cancer bearing mice. Iran J Basic Med Sci 2014;17:231-58.

68. Thompson HJ, Wolfe P, McTiernan A, et al. Wheel running-induced changes in plasma biomarkers and carcinogenic response in the 1-methyl-1-nitrosoureainduced rat model for breast cancer. Cancer Prev Res (Phila) 2010;3:1484-92.

69. Woods JA, Davis JM, Kohut ML, et al. Effects of exercise on the immune response to cancer. Med Sci Sports Exerc 1994;26:1109-15.

70. Aoi W, Naito Y, Takagi T, et al. Regular exercise reduces colon tumorigenesis associated with suppression of iNOS. 
Biochem Biophys Res Commun 2010;399:14-9.

71. Frajacomo FT, Kannen V, Deminice R, et al. Aerobic Training Activates Interleukin 10 for Colon Anticarcinogenic Effects. Medicine and Science in Sports and Exercise 2015;47:1806-13.

72. Ghazizadeh Darband S, Saboory E, Sadighparvar S, et al. The modulatory effects of exercise on the inflammatory and apoptotic markers in rats with 1,2-dimethylhydrazineinduced colorectal cancer. Can J Physiol Pharmacol 2020;98:147-55.

73. McClellan JL, Steiner JL, Day SD, et al. Exercise effects on polyp burden and immune markers in the ApcMin/+ mouse model of intestinal tumorigenesis. Int J Oncol 2014;45:861-8.

74. Mehl KA, Davis JM, Clements JM, et al. Decreased intestinal polyp multiplicity is related to exercise mode and gender in Apc(Min/+) mice. Journal of Applied Physiology 2005;98:2219-25.

75. Zielinski MR, Davis JM, Fadel JR, et al. Influence of chronic moderate sleep restriction and exercise on inflammation and carcinogenesis in mice. Brain Behav Immun 2012;26:672-9.

76. Dos Santos CMM, Diniz VLS, Bachi ALL, et al. Moderate physical exercise improves lymphocyte function in melanoma-bearing mice on a high-fat diet. Nutr Metab (Lond) 2019;16:63.

77. Lee B, Kim G, Jo Y, et al. Aquatic Exercise at Thermoneutral Water Temperature Enhances Antitumor Immune Responses. Immune Netw 2019;19:e10.

78. Yan L, Demars LC. Effects of non-motorized voluntary running on experimental and spontaneous metastasis in mice. Anticancer Res 2011;31:3337-44.

79. Hoffman-Goetz L, MacNeil B, Arumugam Y, et al. Differential effects of exercise and housing condition on murine natural killer cell activity and tumor growth. Int J Sports Med 1992;13:167-71.

80. MacNeil B, Hoffmangoetz L. Effect of Exercise on Natural Cytotoxicity and Pulmonary Tumor-Metastases in Mice. Medicine and Science in Sports and Exercise 1993;25:922-8.

81. Singh MP, Singh G, Singh SM. Role of host's antitumor immunity in exercise-dependent regression of murine T-cell lymphoma. Comp Immunol Microbiol Infect Dis 2005;28:231-48.

82. Zielinski MR, Muenchow M, Wallig MA, et al. Exercise delays allogeneic tumor growth and reduces intratumoral inflammation and vascularization. J Appl Physiol (1985) 2004;96:2249-56
83. Alizadeh AM, Isanejad A, Sadighi S, et al. High-intensity interval training can modulate the systemic inflammation and HSP70 in the breast cancer: a randomized control trial. J Cancer Res Clin Oncol 2019;145:2583-93.

84. Dethlefsen C, Lillelund C, Midtgaard J, et al. Exercise regulates breast cancer cell viability: systemic training adaptations versus acute exercise responses. Breast Cancer Res Treat 2016;159:469-79.

85. Dieli-Conwright CM, Parmentier JH, Sami N, et al. Adipose tissue inflammation in breast cancer survivors: effects of a 16-week combined aerobic and resistance exercise training intervention. Breast Cancer Res Treat 2018;168:147-57.

86. Fairey AS, Courneya KS, Field CJ, et al. Randomized controlled trial of exercise and blood immune function in postmenopausal breast cancer survivors. J Appl Physiol (1985) 2005;98:1534-40.

87. Fairey AS, Courneya KS, Field CJ, et al. Effect of exercise training on C-reactive protein in postmenopausal breast cancer survivors: a randomized controlled trial. Brain Behav Immun 2005;19:381-8.

88. Giallauria F, Gentile M, Chiodini P, et al. Exercise training reduces high mobility group box-1 levels in women with breast cancer: the DIANA (diet and androgens)-5 project. Eur J Prev Cardiol 2014;21:S112.

89. Gómez AM, Martínez C, Fiuza-Luces C, et al. Exercise training and cytokines in breast cancer survivors. Int J Sports Med 2011;32:461-7.

90. Hutnick NA, Williams NI, Kraemer WJ, et al. Exercise and lymphocyte activation following chemotherapy for breast cancer. Med Sci Sports Exerc 2005;37:1827-35.

91. Jones SB, Thomas GA, Hesselsweet SD, et al. Effect of exercise on markers of inflammation in breast cancer survivors: the Yale exercise and survivorship study. Cancer Prev Res (Phila) (philadelphia, pa) 2013;6:109-18.

92. Karimi N, Dabidi Roshan V, Fathi Bayatiyani Z. Individually and Combined Water-Based Exercise With Ginger Supplement, on Systemic Inflammation and Metabolic Syndrome Indices, Among the Obese Women With Breast Neoplasms. Iran J Cancer Prev 2015;8:e3856.

93. Kim JJ, Shin YA, Suk MH. Effect of a 12 -week walking exercise program on body composition and immune cell count in patients with breast cancer who are undergoing chemotherapy. J Exerc Nutrition Biochem 2015;19:255-62.

94. Ligibel JA, Dillon DA, Giobbie-Hurder A, et al. Impact of a pre-operative exercise intervention on breast cancer proliferation and gene expression: results from the Pre- 
Operative Health and Body (PreHAB) Study. Clin Cancer Res 2019;25:5398-406.

95. Mijwel S, Bolam KA, Gerrevall J, et al. Effects of Exercise on Chemotherapy Completion and Hospitalization Rates: the OptiTrain Breast Cancer Trial. Oncologist 2020;25:23-32.

96. Nieman DC, Cook VD, Henson DA, et al. Moderate exercise training and natural killer cell cytotoxic activity in breast cancer patients. Int J Sports Med 1995;16:334-7.

97. Peters C, Lotzerich H, Niemeier B, et al. Influence of a Moderate Exercise Training on Natural-Killer Cytotoxicity and Personality-Traits in Cancer-Patients. Anticancer Res 1994;14:1033-6.

98. Peters C, Lotzerich H, Niemeir B, et al. Exercise, Cancer and the Immune-Response of Monocytes. Anticancer Res 1995; 15:175-9.

99. Rogers LQ, Vicari S, Trammell R, et al. Biobehavioral factors mediate exercise effects on fatigue in breast cancer survivors. Med Sci Sports Exerc 2014;46:1077-88.

100. Rogers LQ, Fogleman A, Trammell R, et al. Effects of a physical activity behavior change intervention on inflammation and related health outcomes in breast cancer survivors: pilot randomized trial. Integr Cancer Ther 2013;12:323-35.

101. Schmidt T, Jonat W, Wesch D, et al. Influence of physical activity on the immune system in breast cancer patients during chemotherapy. J Cancer Res Clin Oncol 2018;144:579-86.

102. Sturgeon KM, Foo W, Heroux M, et al. Change in Inflammatory Biomarkers and Adipose Tissue in BRCA1/2(+) Breast Cancer Survivors Following a Yearlong Lifestyle Modification Program. Cancer Prev Res (Phila) 2018;11:545-50.

103. Tizdast N, Ghazalian F, Gholami M. The Effect of Exercise Type on Inflammatory Markers in Obese Survivors With Breast Cancer: Randomized Control Trial. Health Scope 2016;5.

104.Zimmer P, Baumann FT, Oberste M, et al. Influence of Personalized Exercise Recommendations During Rehabilitation on the Sustainability of Objectively Measured Physical Activity Levels, Fatigue, and FatigueRelated Biomarkers in Patients With Breast Cancer. Integr Cancer Ther 2018;17:306-11.

105. Allgayer H, Nicolaus S, Schreiber S. Decreased interleukin-1 receptor antagonist response following moderate exercise in patients with colorectal carcinoma after primary treatment. Cancer Detect Prev 2004;28:208-13.
106. Devin JL, Hill MM, Mourtzakis M, et al. Acute high intensity interval exercise reduces colon cancer cell growth. J Physiol 2019;597:2177-84.

107.Lee DH, Kim JY, Lee MK, et al. Effects of a 12week home-based exercise program on the level of physical activity, insulin, and cytokines in colorectal cancer survivors: a pilot study. Support Care Cancer 2013;21:2537-45.

108. Lee MK, Kim JY, Kim DI, et al. Effect of home-based exercise intervention on fasting insulin and Adipocytokines in colorectal cancer survivors: a randomized controlled trial. Metabolism 2017;76:23-31.

109. Na YM, Kim MY, Kim YK, et al. Exercise therapy effect on natural killer cell cytotoxic activity in stomach cancer patients after curative surgery. Arch Phys Med Rehabil 2000;81:777-9.

110.Hojan K, Kwiatkowska-Borowczyk E, Leporowska E, et al. Inflammation, cardiometabolic markers, and functional changes in men with prostate cancer: a randomized controlled trial of a 12-month exercise program. Pol Arch Intern Med 2017;127:25-35.

111.Hvid T, Lindegaard B, Winding K, et al. Effect of a 2-year home-based endurance training intervention on physiological function and PSA doubling time in prostate cancer patients. Cancer Causes Control 2016;27:165-74.

112. Guinan EM, Doyle SL, O'Neill L, et al. Effects of a multimodal rehabilitation programme on inflammation and oxidative stress in oesophageal cancer survivors: the ReStOre feasibility study. Support Care Cancer 2017;25:749-56.

113.Jones LW, Eves ND, Peddle CJ, et al. Effects of presurgical exercise training on systemic inflammatory markers among patients with malignant lung lesions. Appl Physiol Nutr Metab 2009;34:197-202.

114. Battaglini CL, Hackney AC, Garcia R, et al. The Effects of an Exercise Program in Leukemia Patients. Integr Cancer Ther 2009;8:130-8.

115. Fiuza-Luces C, Padilla JR, Valentin J, et al. Effects of Exercise on the Immune Function of Pediatric Patients With Solid Tumors: insights From the PAPEC Randomized Trial. Am J Phys Med Rehabil 2017;96:831-7.

116. Glass OK, Inman BA, Broadwater G, et al. Effect of aerobic training on the host systemic milieu in patients with solid tumours: an exploratory correlative study. $\mathrm{Br} \mathrm{J}$ Cancer 2015;112:825-31.

117.Kleckner IR, Kamen C, Cole C, et al. Effects of exercise on inflammation in patients receiving chemotherapy: a 
nationwide NCORP randomized clinical trial. Support

Care Cancer 2019;27:4615-25.

118. Ricci JM, Flores V, Kuroyama I, et al. Pilot Study of Dose-Response Effects of Exercise on Change in C-Reactive Protein, Cortisol, and Health-Related Quality of Life Among Cancer Survivors. Biores Open Access 2018;7:52-62.

119. Sprod LK, Palesh OG, Janelsins MC, et al. Exercise, sleep quality, and mediators of sleep in breast and prostate cancer patients receiving radiation therapy. Community Oncol 2010;7:463-71.

120.Le Noci V, Sommariva M, Bianchi F, et al. Local Administration of Caloric Restriction Mimetics to Promote the Immune Control of Lung Metastases. J Immunol Res 2019;2019:2015892.

121.Pietrocola F, Pol J, Vacchelli E, et al. Caloric Restriction Mimetics Enhance Anticancer Immunosurveillance. Cancer Cell 2016;30:147-60.

122.Di Biase S, Lee C, Brandhorst S, et al. Fasting-Mimicking Diet Reduces HO-1 to Promote T Cell-Mediated Tumor Cytotoxicity. Cancer Cell 2016;30:136-46.

123. Fernandes G, Chandrasekar B, Troyer DA, et al. Dietary lipids and calorie restriction affect mammary tumor incidence and gene expression in mouse mammary tumor virus/v-Ha-ras transgenic mice. Proc Natl Acad Sci U S A 1995;92:6494-8.

124. Hodgson DM, Chiappelli F, Morrow NS, et al. Chronic dietary restriction influences tumor metastasis in the rat: parametric considerations. Nutr Cancer 1997;28:189-98.

125.Sundaram S, Yan L. Time-restricted feeding mitigates high-fat diet-enhanced mammary tumorigenesis in MMTV-PyMT mice. Nutr Res 2018;59:72-9.

126. Harvey AE, Lashinger LM, Otto G, et al. Decreased systemic IGF-1 in response to calorie restriction modulates murine tumor cell growth, nuclear factor-kappaB activation, and inflammation-related gene expression. Mol Carcinog 2013;52:997-1006.

127.Huffman DM, Augenlicht LH, Zhang X, et al. Abdominal obesity, independent from caloric intake, accounts for the development of intestinal tumors in Apc(1638N/+) female mice. Cancer Prev Res (Phila) 2013;6:177-87.

128. Olivo-Marston SE, Hursting SD, Perkins SN, et al. Effects of calorie restriction and diet-induced obesity on murine colon carcinogenesis, growth and inflammatory factors, and microRNA expression. PLoS One 2014;9:e94765.

129. Sun P, Wang HH, He ZY, et al. Fasting inhibits colorectal cancer growth by reducing M2 polarization of tumorassociated macrophages. Oncotarget 2017;8:74649-60.
130. Velázquez KT, Enos RT, Carson MS, et al. Weight loss following diet-induced obesity does not alter colon tumorigenesis in the AOM mouse model. Am J Physiol Gastrointest Liver Physiol 2016;311:G699-G712.

131. Sundaram S, Yan L. Dietary energy restriction reduces high-fat diet-enhanced metastasis of Lewis lung carcinoma in mice. Oncotarget 2016;7:65669-75.

132. Yan L, Sundaram S, Mehus AA, et al. Time-restricted Feeding Attenuates High-fat Diet-enhanced Spontaneous Metastasis of Lewis Lung Carcinoma in Mice. Anticancer Res 2019;39:1739-48.

133. Molina-Aguilar C, Guerrero-Carrillo MJ, EspinosaAguirre JJ, et al. Time-caloric restriction inhibits the neoplastic transformation of cirrhotic liver in rats treated with diethylnitrosamine. Carcinogenesis 2017;38:847-58.

134.Ploeger JM, Manivel JC, Boatner LN, et al. Caloric Restriction Prevents Carcinogen-Initiated Liver Tumorigenesis in Mice. Cancer Prev Res (Phila) 2017;10:660-70.

135. Harvey AE, Lashinger LM, Hays D, et al. Calorie restriction decreases murine and human pancreatic tumor cell growth, nuclear factor-kappaB activation, and inflammation-related gene expression in an insulinlike growth factor-1-dependent manner. PLoS One 2014;9:e94151.

136. Turbitt WJ, Collins SD, Meng H, et al. Increased Adiposity Enhances the Accumulation of MDSCs in the Tumor Microenvironment and Adipose Tissue of Pancreatic Tumor-Bearing Mice and in Immune Organs of Tumor-Free Hosts. Nutrients 2019. doi: 10.3390/ nu11123012.

137.Al-Wahab Z, Tebbe C, Chhina J, et al. Dietary energy balance modulates ovarian cancer progression and metastasis. Oncotarget 2014;5:6063-75.

138. Blando J, Moore T, Hursting S, et al. Dietary energy balance modulates prostate cancer progression in $\mathrm{Hi}-\mathrm{Myc}$ mice. Cancer Prev Res (Phila) 2011;4:2002-14.

139. Konno A, Hishinuma K, Hashimoto Y, et al. Dietary restriction reduces the incidence of 3-methylcholanthreneinduced tumors in mice: close correlation with its potentiating effect on host $\mathrm{T}$ cell functions. Cancer Immunol Immunother 1991;33:293-8.

140.Matsuzaki J, Yamaji R, Kiyomiya K, et al. Implanted tumor growth is suppressed and survival is prolonged in sixty percent of food-restricted mice. J Nutr 2000;130:111-5.

141. Mukhopadhyay P, Dasgupta J, Senyal U, et al. Influence of Dietary Restriction and Soybean Supplementation on the Growth of a Murine Lymphoma and Host Immune 
Function. Cancer Letters 1994;78:151-7.

142. Mulrooney TJ, Marsh J, Urits I, et al. Influence of caloric restriction on constitutive expression of NF-kappaB in an experimental mouse astrocytoma. PLoS One 2011;6:e18085.

143. Turbitt WJ, Demark-Wahnefried W, Peterson CM, et al. Targeting Glucose Metabolism to Enhance Immunotherapy: Emerging Evidence on Intermittent Fasting and Calorie Restriction Mimetics. Front Immunol 2019;10:1402.

144. Campbell KL, Van Patten CL, Neil SE, et al. Feasibility of a Lifestyle Intervention on Body Weight and Serum Biomarkers in Breast Cancer Survivors with Overweight and Obesity. J Acad Nutr Diet 2012;112:559-67.

145.Demark-Wahnefried W, Rogers LQ, Gibson JT, et al. Randomized trial of weight loss in primary breast cancer: Impact on body composition, circulating biomarkers and tumor characteristics. Int J Cancer 2020;146:2784-96.

146. Pakiz B, Flatt SW, Bardwell WA, et al. Effects of a weight loss intervention on body mass, fitness, and inflammatory biomarkers in overweight or obese breast cancer survivors. Int J Behav Med 2011;18:333-41.

147. Saxton JM, Scott EJ, Daley AJ, et al. Effects of an exercise and hypocaloric healthy eating intervention on indices of psychological health status, hypothalamic-pituitary-

Cite this article as: $\mathrm{Xu} \mathrm{Y,} \mathrm{Rogers} \mathrm{CJ.} \mathrm{Impact} \mathrm{of} \mathrm{physical}$ activity and energy restriction on immune regulation of cancer. Transl Cancer Res 2020;9(9):5700-5731. doi: 10.21037/ tcr.2020.03.38 adrenal axis regulation and immune function after earlystage breast cancer: a randomised controlled trial. Breast cancer research 2014;16:R39.

148. Swisher AK, Abraham J, Bonner D, et al. Exercise and dietary advice intervention for survivors of triple-negative breast cancer: effects on body fat, physical function, quality of life, and adipokine profile. Support Care Cancer 2015;23:2995-3003.

149. Brown JC, Yung RL, Gobbie-Hurder A, et al. Randomized trial of a clinic-based weight loss intervention in cancer survivors. J Cancer Surviv 2018;12:186-95.

150.Hornyák L, Dobos N, Koncz G, et al. The Role of Indoleamine-2,3-Dioxygenase in Cancer Development, Diagnostics, and Therapy. Front Immunol 2018;9:151.

151. Pardoll DM. The blockade of immune checkpoints in cancer immunotherapy. Nat Rev Cancer 2012;12:252-64.

152. Madeo F, Carmona-Gutierrez D, Hofer SJ, et al. Caloric Restriction Mimetics against Age-Associated Disease: Targets, Mechanisms, and Therapeutic Potential. Cell Metab 2019;29:592-610.

153. Bland KA, Zadravec K, Landry T, et al. Impact of exercise on chemotherapy completion rate: A systematic review of the evidence and recommendations for future exercise oncology research. Crit Rev Oncol Hematol 2019;136:79-85. 


\section{(I) PubMed}

("exercise"[mesh] OR "exercise"[tiab] OR "exercises"[tiab] OR "physical activity"[tiab] OR "physical activities"[tiab] OR "physical fitness"[mesh] OR "physical fitness"[tiab] OR "aerobic activity"[tiab] OR "aerobic activities"[tiab] OR "aerobic training"[tiab] OR "endurance training"[tiab] OR "physical endurance"[tiab] OR "physical conditioning"[tiab] OR "walk"[tiab] OR "walking"[tiab] OR "swim"[tiab] OR "swimming"[tiab] OR "running"[tiab] OR “jog"[tiab] OR "jogging”[tiab] OR "cardiovascular activity"[tiab] OR "cardiovascular activities"[tiab] OR "cardiometabolic"[tiab]

OR

"caloric restriction"[mesh] OR "caloric restriction"[tiab] OR "calorie restriction"[tiab] OR "low calorie diet"[tiab] OR "low-calorie diet"[tiab] OR "low calorie diets"[tiab] OR "low-calorie diets"[tiab] OR "diet restriction"[tiab] OR "dietary restriction"[tiab] OR "energy restriction"[tiab] OR "weight loss"[mesh] OR "weight loss"[tiab] OR "weight losses"[tiab] OR "weight-loss"[tiab] OR "weight-losses"[tiab] OR "weight reduction"[tiab] OR "weight reductions"[tiab] OR "fasting"[mesh] OR "fasting"[tiab] OR "intermittent fasting"[tiab] OR "intermittent fastings" [tiab] OR "time restricted feeding"[tiab] OR "time restricted feedings" [tiab] OR "time-restricted feeding"[tiab] OR "time-restricted feedings"[tiab])

AND

(“immune"[tiab] OR "immunity"[mesh] OR "immunity"[tiab] OR "immune system"[mesh] OR "immune system phenomena"[mesh] OR "immunotherapy"[mesh] OR "immunotherapy"[tiab] OR "immunotherapies"[tiab] OR "leukocyte"[tiab] OR "leukocytes"[tiab] OR "lymphocyte"[tiab] OR "lymphocytes"[tiab] OR “T cell”[tiab] OR "T cells"[tiab] OR "B cell"[tiab] OR "B cells"[tiab] OR "natural killer"[tiab] OR “NK cell”[tiab] OR "NK cells"[tiab] OR “monocyte"[tiab] OR "monocytes"[tiab] OR “macrophage"[tiab] OR "macrophages"[tiab] OR "dendritic cell"[tiab] OR "dendritic cells"[tiab] OR "neutrophil"[tiab] OR "neutrophils"[tiab] OR "myeloid-derived suppressor cells"[mesh] OR "myeloid-derived suppressor cell"[tiab] OR "myeloid-derived suppressor cells"[tiab] OR "myeloid derived suppressor cell"[tiab] OR "myeloid derived suppressor cells"[tiab] OR "regulatory T cell”[tiab] OR "regulatory T cells"[tiab] OR "Treg”"[tiab] OR "Tregs"[tiab] OR "immunosuppression"[tiab] OR "antigen presentation"[tiab] OR "cytokine"[tiab] OR "cytokines"[tiab] OR "chemokine"[tiab] OR "chemokines"[tiab] OR "antibodies"[mesh] OR "antibody"[tiab] OR "antibodies"[tiab] OR "immunoglobulins"[mesh] OR "immunoglobulin"[tiab] OR “immunoglobulins"[tiab] OR “inflammation”[mesh] OR “inflammation"[tiab] OR "inflammations"[tiab] OR "inflammatory"[tiab])

AND

(“neoplasms"[mesh] OR "neoplasms"[tiab] OR “neoplasm"[tiab] OR "neoplasia”[tiab] OR "neoplasias"[tiab] OR "cancer”[tiab] OR "cancers"[tiab] OR “tumor"[tiab] OR "tumors"[tiab] OR “tumour”[tiab] OR “tumours”[tiab] OR "malignancy"[tiab] OR "malignancies”[tiab])

NOT review[pt]

AND English[lang]

(II) Web of Science

TOPIC: ("exercise" OR "exercises" OR "physical activity" OR "physical activities" OR "physical fitness" OR "aerobic activity" OR "aerobic activities" OR "aerobic training" OR "endurance training" OR "physical endurance" OR "physical conditioning" OR "walk" OR "walking" OR "swim" OR "swimming" OR "running" OR "jog" OR "jogging" OR "cardiovascular activity" OR "cardiovascular activities" OR "cardiometabolic"

OR

"caloric restriction" OR "calorie restriction" OR "low calorie diet" OR "low-calorie diet" OR "low calorie diets" OR "low-calorie diets" OR "diet restriction" OR "dietary restriction" OR "energy restriction" OR "weight loss" OR "weight losses" OR "weight-loss" OR "weightlosses" OR "weight reduction" OR "weight reductions" OR "fasting" OR "intermittent fasting" OR "intermittent fastings" OR "time restricted feeding" OR "time restricted feedings" OR "time-restricted feeding" OR "time-restricted feedings")

AND

TOPIC: ("immune" OR "immunity" OR "immunotherapy" OR "immunotherapies" OR "leukocyte" OR "leukocytes" OR "lymphocyte" OR "lymphocytes" OR "T cell" OR "T cells" OR "B cell" OR "B cells" OR "natural killer" OR "NK cell" OR "NK cells" OR "monocyte" OR "monocytes" OR "macrophage" OR "macrophages" OR "dendritic cell" OR "dendritic cells" OR "neutrophil" OR "neutrophils" OR "myeloid-derived suppressor cell" OR "myeloid-derived suppressor cells" OR "myeloid derived suppressor cell" OR "myeloid derived suppressor cells" OR "regulatory T cell" OR "regulatory T cells" OR "Treg" OR "Tregs" OR "immunosuppression" OR "antigen presentation" OR "cytokine" OR "cytokines" OR "chemokine" OR "chemokines" OR "antibody" OR "antibodies" OR "immunoglobulin" OR "immunoglobulins" OR "inflammation" OR "inflammations" OR "inflammatory")

AND

TOPIC: (“neoplasm" OR “neoplasms" OR "neoplasia” OR "neoplasias" OR "cancer” OR "cancers" OR "tumor" OR "tumors" OR "tumour" OR "tumours" OR "malignancy" OR "malignancies")

AND

LANGUAGE: English

NOT

DOCUMENT TYPES: Review

(III) CENTRAL

ti.ab.kw.: ("exercise" OR "physical activity" OR "aerobic activity" OR "aerobic training" OR "endurance training" OR "caloric restriction" OR "calorie restriction" OR "dietary restriction" OR "energy restriction" OR "weight loss" OR "weight reduction")

AND

ti.ab.kw.: ("immune" OR "immunity" OR "immunotherapy" OR "leukocyte" OR "lymphocyte" OR "T cell" OR "B cell” OR "natural killer" OR "NK cell" OR "monocyte" OR "macrophage" OR "dendritic cell" OR "neutrophil" OR "myeloid-derived suppressor cell" OR "cytokine" OR "chemokine" OR "antibody" OR "immunoglobulin" OR "inflammation" OR "inflammations" OR "inflammatory")

AND

ti.ab.kw.: ("neoplasm” OR "neoplasia” OR "cancer” OR "tumor” OR "malignancy") 

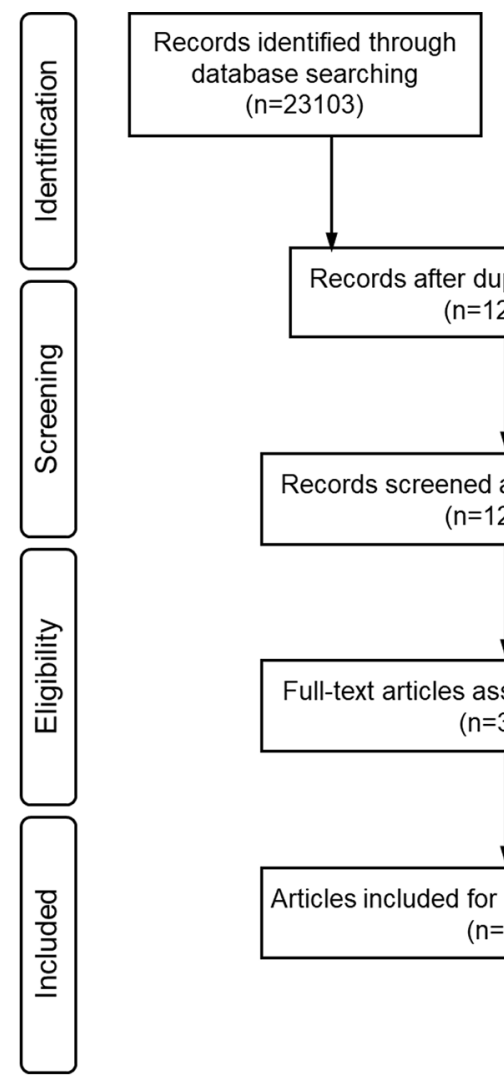

Additional records identified

through other sources $(n=23103)$ $(n=14)$

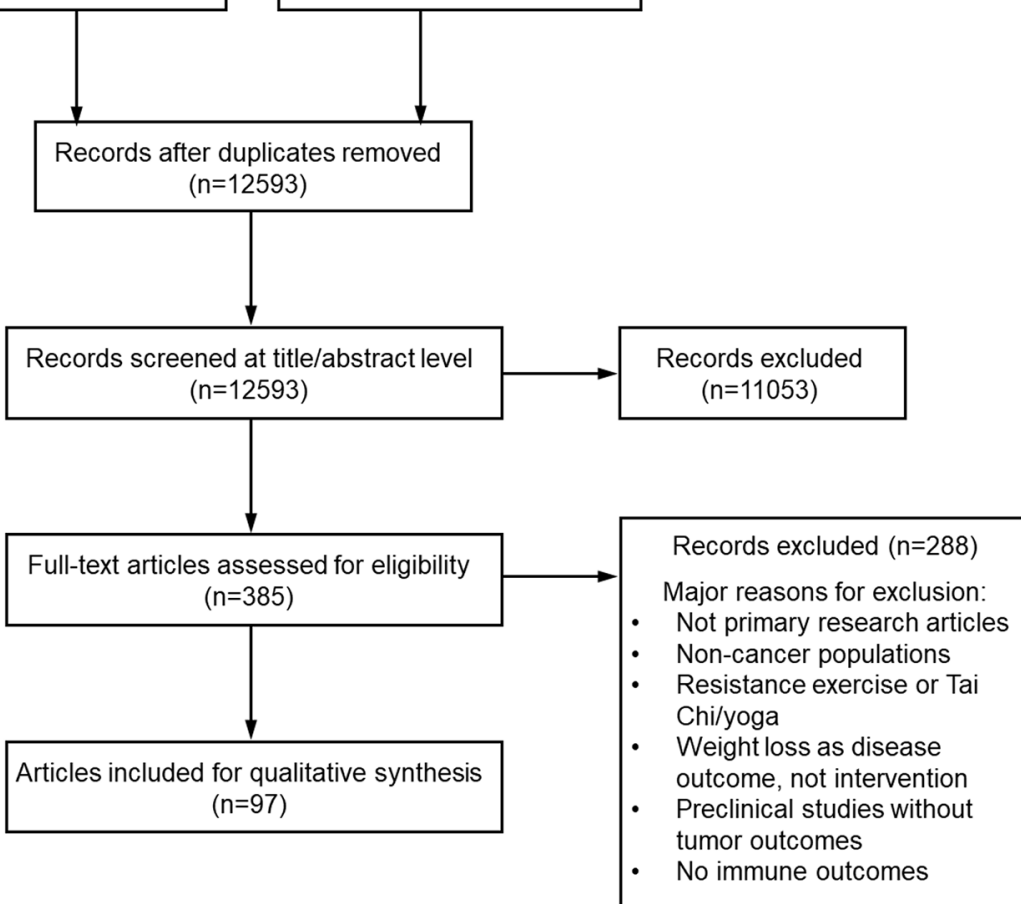

Figure S1 PRISMA flow diagram of the study selection process. 